\title{
Absolute Rate Calculations for Atom Abstractions by Radicals: Energetic, Structural and Electronic Factors
}

\author{
Luis G. Arnaut, ${ }^{*}$ Alberto A. C. C. Pais, Sebastião J. Formosinho, ${ }^{\dagger}$ and \\ Monica Barroso \\ Contribution from the Universidade de Coimbra, Departamento de Química, \\ P-3049 Coimbra Codex, Portugal \\ Received November 11, 2002; E-mail: Igarnaut@ci.uc.pt.
}

\begin{abstract}
We calculate transition-state energies of atom-transfer reactions from reaction energies, electrophilicity indices, bond lengths, and vibration frequencies of the reactive bonds. Our calculations do not involve adjustable parameters and uncover new patterns of reactivity. The generality of our model is demonstrated comparing the vibrationally adiabatic barriers obtained for 100 hydrogen-atom transfers with the corresponding experimental activation energies, after correction for the heat capacities of reactants and transition state. The rates of half of these reactions are calculated using the Transition-State Theory with the vibrationally adiabatic path of the Intersecting-State Model and the semiclassical correction for tunneling (ISM/ScTST). The calculated rates are within an order of magnitude of the experimental ones at room temperature. The temperature dependencies and kinetic isotope effects of selected systems are also in good agreement with the available experimental data. Our model elucidates the roles of the reaction energy, electrophilicity, structural parameters, and tunneling in the reactivity of these systems and can be applied to make quantitative predictions for new systems.
\end{abstract}

\section{Introduction}

The current understanding of structure-reactivity relationships remains deeply rooted in concepts of physical-organic chemistry, such as that of a "family of reactions". Empirical and semiquantitative relations have been employed to systematize reactivity trends and identify unusual behavior. ${ }^{1}$ The predictive power of such relations is generally restricted to structurally related reactants and their use for classes other than those used in their development may be discouraged. ${ }^{2}$ They will continue to be useful to rationalize the immense compilations of rate constants for atom abstraction reactions, ${ }^{3}$ but there is an increasing need for physically meaningful models that can quantitatively link traditional reactivity indices such as the reaction energy, polar effect, and structural parameters, ${ }^{4,5}$ to the making of reaction energy-barriers. On the other hand, new reactivity indices have emerged from density functional theory (DFT), such as those of chemical potential and chemical hardness. ${ }^{6}$ Although numerical methods fulfill the need for accurate calculations of reaction barriers, the result of one calculation may not be chemically intuitive and does not suffice to predict chemical reactivity. Knowing one energy barrier does not tell us much if anything about the structure, nature, energy,

†Also at Universidade Católica Portuguesa, Escola de Ciências e Tecnologia, 3500 Viseu, Portugal.

(1) Lee, I.-S. H.; Chow, K.-H.; Kreevoy, M. M. J. Am. Chem. Soc. 2002, 124, 7755.

(2) Kwok, E. S. C.; Atkinson, R. Atmospheric Environment 1995, 29, 1685.

(3) Snelgrove, D. W.; Lusztyk, J.; Banks, J. T.; Mulder, P.; Ingold, K. U. J. Am. Chem. Soc. 2001, 123, 469.

(4) Roberts, B. P. J. Chem. Soc., Perkin Trans. 2 1996, 2719.

(5) Heidbrink, J. L.; Ramírez-Arizmendi, T., K. K.; Guler, L.; Kenttämaa, H. I. J. Phys. Chem. 2001, 105, 7875 .

(6) Ayers, P. W.; Parr, R. G. J. Am. Chem. Soc. 2001, 123, 2007.

5236 - J. AM. CHEM. SOC. 2003, 125, 5236-5246 and so forth, of another energy barrier. ${ }^{7}$ Recent developments have combined rate-equilibrium relationships with ab initio and DFT calculations. ${ }^{8}$ Further advances in this field must consider the above-mentioned reactivity indices, rationalize the existing theoretical and experimental data, and predict new reactivity trends.

The objective of this work is to relate quantitatively the electronic and molecular structure of the reactants and products with the corresponding reaction rates. The relation developed here is rooted in the Intersecting-State Model (ISM) originally developed by Formosinho and co-workers. ${ }^{9}$ In this work, we present, for the first time, fast and reliable estimates of absolute rates of very different atom transfers, using only information on the reactants and products. We employ the term "absolute" to mean that the actual rate constants are calculated exclusively from thermodynamic and spectroscopic information on the reactants and products. The calculations do not involve the fitting of any parameters to the kinetic data.

The remaining of this work is divided in three parts. First, we formulate the model, examine its foundations and compare ISM classical energies and reaction paths with those of ab initio calculations for 20 prototypical atom-transfer reactions. These systems were selected because high-level ab initio calculations

(7) Shurki, A.; Shaik, S. J. Mol. Struct. (THEOCHEM) 1998, 424, 37

(8) Guthrie, J. P.; Pitchko, V. J. Am. Chem. Soc. 2000, 122, 5520.

(9) (a) Varandas, A. J. C.; Formosinho, S. J. J. Chem. Soc., Faraday Trans. 2 1986, 82, 953. (b) Formosinho, S. J. Theoretical and Computational Models for Organic Chemistry; Formosinho, S. J., Csizmadia, I. G., Arnaut, L. G., Ed.; NATO ASI, Kluwer: Dordrecht, 1991; p. 159. (c) Arnaut, L. G.; Formosinho, S. J. Homogeneous Photocatalysis; Chanon, M., Ed.; Wiley: 1997; p. 55. (d) Pais, A. A. C. C.; Arnaut, L. G.; Formosinho, S. J. J. Chem. Soc., Perkin Trans. 2 1998, 2577-2584. (e) Arnaut, L. G.; Pais, A. A. C. C.; Formosinho, S. J. J. Mol. Struct. 2001, 563/564, 1. 
are available for comparison and because they involve a large diversity of bonds in the reaction coordinate. Then, we assess the generality of our model comparing calculated and experimental activation energies of 100 different reactions, mostly measured within the 500-1000 K temperature range, for which the Arrhenius equation provides an adequate description of the experimental data. The application of the model to such a large set of reactions discloses new reactivity trends. Finally, we calculate the rate-constants of $\mathrm{X}+\mathrm{HR}$ reactions and halogenatom transfers. We selected reactions where $\mathrm{X}=\mathrm{H}, \mathrm{OH}$, or $\mathrm{CH}_{3}$ for their importance in fundamental, atmospheric and combustion chemistry. For some prototypical systems the comparison with experimental data is made over a large range of temperatures and includes kinetic isotope effects (KIE).

2. Classical Transition-States. This new formulation of ISM is totally based in relations that lie outside the field of reaction kinetics and has no adjustable parameters. Only the fundamental equations of the model are presented here. The details of the algorithm are presented as Supporting Information. The implementation of the algorithm in PC or Mac computers is available from the authors via the Internet.

The correlation between reactant $\left(n_{\mathrm{BC}}\right)$ and $\left(n_{\mathrm{AB}}\right)$ product bond-orders in atom-transfer reactions

$$
\mathrm{A}+\mathrm{BC} \rightarrow \mathrm{AB}+\mathrm{C}
$$

has been used to define the reaction coordinate $n^{10}$

$$
n=n_{\mathrm{AB}}=1-n_{\mathrm{BC}}
$$

that varies from 0 in the reactants to 1 in the products. This reaction coordinate is known to agree well with the actual minimum-energy path for a variety of potential energy surfaces (PES). ${ }^{11,12}$ This agreement shows that the electronic redistribution between single bonds is reflected in the conservation of the bond order along the reaction coordinate.

On the other hand, Pauling's relation between equilibrium bond orders $(n)$ and bond lengths $(l)$

$$
l-l_{1}=-a \ln (n)
$$

where $a$ is a constant and $l_{1}$ equilibrium length of the corresponding single bond, can be conveniently generalized to relate transition-state bond orders to bond lengths

$$
l_{\mathrm{BC}}^{\ddagger}-l_{\mathrm{BC}, \mathrm{eq}}=-a^{\prime}\left(l_{\mathrm{BC}, \mathrm{eq}}+l_{\mathrm{AB}, \mathrm{eq}}\right) \ln \left(n_{\mathrm{BC}}^{\ddagger}\right)
$$

We replaced the scaling by $a$ in eq 3 with the scaling by $a^{\prime}\left(l_{\mathrm{AB}, \text { eq }}+l_{\mathrm{BC}, \mathrm{eq}}\right)$ because longer bonds will stretch out more from equilibrium to the transition-state configurations than shorter ones, and because two bonds are implicated in the transition state. The constant relating transition-state bond length to bond order is different from that relating these quantities in equilibrium. Thus, the value of $a^{\prime}$ must be obtained from an independent source.

The most convenient source for obtaining the value of $a^{\prime}$ is the PES of the $\mathrm{H}+\mathrm{H}_{2}$ system. For symmetry reasons, this system must have $n_{\mathrm{BC}}^{\ddagger}=n_{\mathrm{AB}}^{\ddagger}=0.5$. The equilibrium and transition-state bond lengths of the DMBE-PES are $l_{\mathrm{BC}, \text { eq }}=l_{\mathrm{AB}, \text { eq }}$

(10) Johnston, H. S.; Parr, C. J. Am. Chem. Soc. 1963, 85, 2544.

(11) Truhlar, D. G. J. Am. Chem. Soc. 1972, 94, 7584.

(12) Agmon, N.; Levine, R. D. J. Chem. Phys. 1979, 71, 3034.
$=0.7414 \AA$ and $l_{\mathrm{BC}}^{\ddagger}=l_{\mathrm{AB}}^{\ddagger}=0.9287 \AA .{ }^{13}$ These values indicate that each $\mathrm{H}-\mathrm{H}$ bond extends by $0.1873 \AA$ along the minimumenergy path, and eq 4 gives $a^{\prime}=0.182 .{ }^{14}$ This value of $a^{\prime}$ is appropriate for calculating transition-state structures and classical-potential energies $\left(\Delta^{\ddagger} V_{\mathrm{cl}}\right)$.

Qualitatively, a PES can be viewed as an interpolation between the potential energies of the reagents and of the products. ${ }^{12}$ The simplest, linear interpolation between the potential energies of the fragments $\mathrm{BC}$ and $\mathrm{AB}$ along the reaction coordinate is

$$
V_{\mathrm{cl}}=(1-n) V_{\mathrm{BC}}+n V_{\mathrm{AB}}+n \Delta \mathrm{V}^{0}
$$

where the variation in the potential energy of the fragments, $V_{\mathrm{BC}}$ and $V_{\mathrm{AB}}$, can be represented by Morse curves, and $\Delta V^{0}=$ $D_{\mathrm{BC}}-D_{\mathrm{AB}}$ is the classical reaction energy. $D_{\mathrm{BC}}$ and $D_{\mathrm{AB}}$ are the dissociation energies of the diatomic molecules $\mathrm{BC}$ and $\mathrm{AB}$. When Morse curves are expressed in terms of the bond orders rather than in terms of bond extensions, we obtain

$$
\begin{gathered}
V_{\mathrm{BC}}=D_{\mathrm{BC}}\left\{1-\exp \left[\beta_{\mathrm{BC}} a^{\prime}\left(l_{\mathrm{AB}, \mathrm{eq}}+l_{\mathrm{BC}, \mathrm{eq}}\right) \ln \left(n_{\mathrm{BC}}\right)\right]\right\}^{2} \\
V_{\mathrm{AB}}=D_{\mathrm{AB}}\left\{1-\exp \left[\beta_{\mathrm{AB}} a^{\prime}\left(l_{\mathrm{AB}, \mathrm{eq}}+l_{\mathrm{BC}, \mathrm{eq}}\right) \ln \left(n_{\mathrm{AB}}\right)\right]\right\}^{2}
\end{gathered}
$$

Following the expressive terminology of Evans and Polanyi, ${ }^{15}$ the "inertia" of the reaction is given by the extension of the $\mathrm{BC}$ bond and by the repulsion between $\mathrm{B}$ and $\mathrm{A}$, each linearly dependent on its bond order (or exponentially dependent on its bond extension). Once the transition state is reached, these factors became the "driving force" of the reaction, that is, both the release of the repulsion between $\mathrm{B}$ and $\mathrm{C}$ and the formation of the $\mathrm{AB}$ bond contribute to the stabilization of the products. The transition-state bond order, $n^{\ddagger}$, is given by the value of $n$ at the maximum of the reaction path. At this point, the binding and repulsion forces are balanced.

$\mathrm{A}$ and $\mathrm{C}$ may be atoms or groups of atoms. They can be regarded as ligands or substituents in the $\{\text { A...B...C }\}^{\ddagger}$ transition state and may increase its electronic density relative to that of our reference system, $\{\mathrm{H} . . . \mathrm{H} . . . \mathrm{H}\}^{\ddagger}$. Such an increase in electronic density has been regarded as a formal enhanced bonding of the transition state. ${ }^{16} \mathrm{We}$ have shown that the simplest modification of the bond order that accounts for its eventual enhancement at the transition state but preserves its location and respects the asymptotic limits, is ${ }^{9}$

$$
\begin{gathered}
n_{\mathrm{AB}}^{\ddagger}=n^{(1 / m)} \\
n_{\mathrm{BC}}^{\ddagger}=(1-n)^{1 / m}
\end{gathered}
$$

where $m \geq 1$. The increase in electronic density at the transition state depends on the value of $m$. Thus, $m$ is a measure of electron count. An appropriate expression for $m$ should take into consideration the change of electronic density when substituents are introduced in our reference reaction, $\mathrm{H}+\mathrm{H}_{2}$, for which we assign $m=1$.

(13) Varandas, A. J. C.; Brown, F. B.; Mead, C. A.; Truhlar, D. G.; Garrett, B. C. J. Chem. Phys. 1987, 86, 6258.

(14) The first application of ISM involved the scaling to the activation energy of the $\mathrm{H}+\mathrm{H}_{2}$ reaction and the factor $a^{\prime}=0.156$ was obtained.

(15) Evans, M. G.; Polanyi, M. Trans. Faraday Soc. 1938, 34, 11

(16) Nalewajski, R. F.; Formosinho, S. J.; Varandas, A. J. C.; Mrozek, J. Int. J. Quantum Chem. 1994, 52, 1153. 


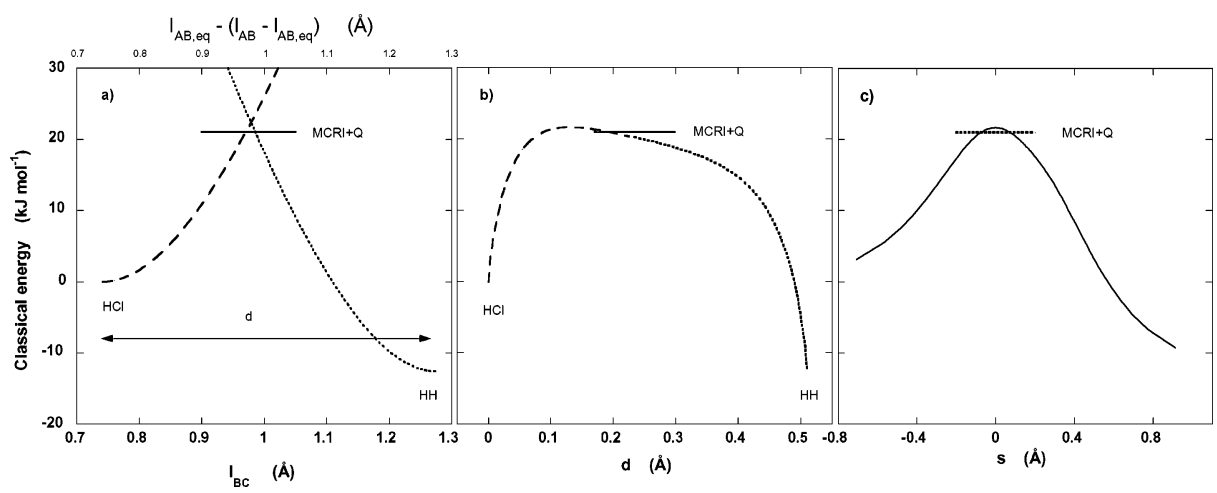

Figure 1. (a) Intersection of the Morse curve representing $\mathrm{HCl}$ with that representing $\mathrm{H}_{2}$, as a function of the $\mathrm{HCl}$ and $\mathrm{HH}$ extensions from their equilibrium to their transition-state configurations. (b) Interaction of Morse curves according to eq 5, as a function of the same reactant and product bond extensions. (c) Interaction of the same Morse curves according to eq 5 as a function of the distance along the reaction coordinate measured from the transition state. The line identified by MRCI $+\mathrm{Q}$ is the energy calculated for this system using quantum-mechanical methods described in Table 2.

The capability of a ligand to donate precisely one electron is measured by its ionization potential. However, if we wish to measure to what extent partial electron transfer contributes to the lowering of the total binding energy by maximal flow of electrons, it is more appropriate to use the electrophilicity index recently proposed by Parr $^{17}$

$$
m=\frac{I_{\mathrm{p}}+E_{\mathrm{A}}}{I_{\mathrm{p}}-E_{\mathrm{A}}}
$$

where $I_{\mathrm{P}}$ is the ionization potential and $E_{\mathrm{A}}$ is the electron affinity of the ligand. This definition of $m$ corresponds to the ratio between the negative of the chemical potential and the chemical hardness. The value of $m$ can be calculated using $I_{\mathrm{P}}(\mathrm{A})$ and $E_{\mathrm{A}}(\mathrm{A}), I_{\mathrm{P}}(\mathrm{C})$, and $E_{\mathrm{A}}(\mathrm{C}), I_{\mathrm{P}}(\mathrm{A})$, and $E_{\mathrm{A}}(\mathrm{C})$, or $I_{\mathrm{P}}(\mathrm{C})$, and $E_{\mathrm{A}^{-}}$ (A). The best way to change the number of electrons or the chemical potential of a molecule is the way that minimizes its hardness. ${ }^{18}$ Thus, we chose the combination that maximizes the value of $m$. This combination minimizes the transition-state energy. It is interesting to note that systems such as $\mathrm{H}+\mathrm{HCl}$ ( $\mathrm{H}$-abstraction) and $\mathrm{HCl}+\mathrm{H}(\mathrm{Cl}$ exchange) share the same PES and the same value of $m$. Many other reactivity models relate the height of the reaction barrier to the electronic properties of the reactants. Particularly insightful is the Valence-Bond approach to reactivity formulated by Shaik, ${ }^{19}$ that expresses the barrier height as a fraction of the difference between the ionization potential of the donor and the electron affinity of the acceptor, ${ }^{20}$ i.e., the chemical hardness.

Earlier formulations of ISM used the intersection between the $\mathrm{BC}$ and $\mathrm{AB}$ rotated Morse curves to locate the transition state, ${ }^{9}$ rather than the interaction expressed by eq 5 . The two approaches give identical activation energies for symmetrical reactions and have the same limiting values for very exothermic and very endothermic reactions. For intermediate cases they also lead to very similar results, as illustrated in Figure 1 for the $\mathrm{H}$ $+\mathrm{HCl} \rightarrow \mathrm{H}_{2}+\mathrm{Cl}$ reaction. This figure shows how the intersection of rotated Morse curves is related to their interaction. First, we express the rotated Morse curves as a function of the reaction coordinate defined by the reactant and product bond extensions. Then, we express the interaction of the Morse curves given by eq 5 as a function of the same reaction coordinate,

(17) Parr, R. G.; Szentpály, L. v.; Liu, S. J. Am. Chem. Soc. 1999, 121, 1922

(18) Ayers, P. W. Parr, R G. J. Am. Chem Soc. 2000, 122, 2010.

(19) Shaik, S. S. J. Am. Chem. Soc. 1981, 103, 3692.

(20) Pross, A.; Shaik, S. Acc. Chem. Res. 1983, 16, 363.
$\left(l_{\mathrm{BC}}-l_{\mathrm{BC}, \mathrm{eq}}\right)$ in the reactants side and $\left(l_{\mathrm{AB}}-l_{\mathrm{AB}, \mathrm{eq}}\right)$ in the products side, to show that the classical energy barrier is approximately the same as for the intersection of the curves. Finally, we convert the bond extensions in the distance along the reaction coordinate measured from the transition state, $s=$ $\pm \sqrt{ }\left[\left(l_{\mathrm{BC}}-l_{\mathrm{BC}}^{\ddagger}\right)^{2}+\left(l_{\mathrm{AB}}-l_{\mathrm{AB}}^{\ddagger}\right)^{2}\right]$, which is the usual reaction coordinate for atom transfers. Although the energy of the transition state is approximately the same for both approaches, only the interaction of the Morse curves can account for the energy variation along the whole reaction path. According to the new formalism, the theoretical model should now be called "interacting-state", rather than "intersecting-state", model. The acronym ISM can still be used to reflect both the origin of the model and its present formulation.

The new formulation of ISM provides a simple method to relate electronic ( $I_{\mathrm{P}}$ and $\left.E_{\mathrm{A}}\right)$, thermochemical $\left(D_{\mathrm{BC}}\right.$ and $\left.D_{\mathrm{AB}}\right)$, structural $\left(l_{\mathrm{BC}, \text { eq }}\right.$ and $\left.l_{\mathrm{AB}, \mathrm{eq}}\right)$ and spectroscopic $\left(\beta_{\mathrm{BC}}\right.$ and $\left.\beta_{\mathrm{AB}}\right)$ properties of reactants and products to reaction barriers $\left(\Delta^{\ddagger} V_{\mathrm{cl}}\right)$. This formulation does not involve the fitting of any parameters to the kinetic data. The transition-state energy is estimated from an analytical expression that only uses chemical data tabulated for the reactants and products, Table 1.

Table 2 presents a set of systems that was studied in great detail by ab initio methods and provides the grounds for testing the accuracy of ISM classical barriers. ISM barriers, $\Delta^{\ddagger} V_{\mathrm{cl}}$, are in excellent agreement with high-level ab initio barriers, $V^{\ddagger}$, Figure 2. This is a remarkable achievement, considering that our model employs analytical expressions without adjustable parameters and that the systems were selected for their diversity.

The barriers and rates of the $\mathrm{H}$-atom transfers between hydrogen and carbon centered radicals with $\mathrm{sp}^{3}$ hybridization, were calculated with $m=1$. The actual values of $m$ are slightly larger than unity and lead to ca. $1 \mathrm{~kJ} \mathrm{~mol}^{-1}$ lower barriers. The choice of $m=1$ was motivated both by theoretical and practical reasons. The electronic structure of the transition state of these reactions closely resembles that of the reference reaction, $\mathrm{H}+$ $\mathrm{H}_{2}$, for which we set $m=1$ but that according to eq 8 should have $m=1.117$. The change in the electronic density relative to the reference system is very small and justifies the use of $m$ $=1$ for this type of systems. Additionally, the electronic parameters of some hydrocarbons are subject to substantial error and may not even be known, but the corresponding $\mathrm{H}$ abstraction rates by hydrogen atoms can still be calculated with good accuracy, as will be shown below. 
Table 1. Bond Lengths, Bond Dissociation Energies, Vibrational Frequencies of the Molecules, and Ionization Potentials and Electron Affinities of the Radicals Employed in the Calculation of the Energy Barriers of Atom Transfer Reactions

\begin{tabular}{|c|c|c|c|c|c|}
\hline & $\begin{array}{l}l_{e q}{ }^{a} \\
(\hat{A})\end{array}$ & $\begin{array}{c}D_{298^{a}} \\
\left(\mathrm{KJ} \mathrm{mol}^{-1}\right)\end{array}$ & $\begin{array}{c}\omega_{e}^{b} \\
\left(\mathrm{~cm}^{-1}\right)\end{array}$ & $\begin{array}{l}l_{p^{b}} \\
(\mathrm{eV})\end{array}$ & $\begin{array}{l}E_{A^{b}} \\
(\mathrm{eV})\end{array}$ \\
\hline $\mathrm{H}_{2}$ & 0.74144 & 435.99 & $4161^{c}$ & 13.598 & 0.75419 \\
\hline $\mathrm{CH}_{4}$ & 1.0870 & 438.9 & 2917 & 9.843 & 0.08 \\
\hline $\mathrm{CH}_{3} \mathrm{CH}_{3}$ & 1.0940 & 423.0 & 2954 & 8.117 & -0.26 \\
\hline $\mathrm{CH}_{3} \mathrm{CH}_{2} \mathrm{CH}_{3}$ & 1.107 & 409.1 & 2887 & 7.37 & -0.321 \\
\hline$\left(\mathrm{CH}_{3}\right)_{3} \mathrm{CH}$ & 1.122 & 404.3 & $2890^{e}$ & 6.70 & -0.156 \\
\hline $\mathrm{CH}_{3} \mathrm{COCH}_{3}$ & 1.103 & 411.3 & 2939 & & \\
\hline $\mathrm{CH}_{3} \mathrm{OCH}_{3}$ & 1.121 & 402.2 & 2817 & 6.90 & -0.017 \\
\hline $\mathrm{CH}_{3} \mathrm{OH}$ & 1.0936 & 401.8 & 2844 & 7.562 & \\
\hline $\mathrm{CH}_{3} \mathrm{CHO}$ & 1.128 & 373.8 & 2822 & 7.00 & 0.423 \\
\hline $\mathrm{CH}_{2} \mathrm{O}$ & 1.116 & 368.5 & 2783 & 8.14 & 0.313 \\
\hline $\mathrm{CH}_{3} \mathrm{C}_{6} \mathrm{H}_{5}$ & 1.111 & 375.7 & $2934^{d}$ & 7.2488 & 0.912 \\
\hline $\mathrm{CH}_{2}=\mathrm{CH}_{2}$ & 1.087 & 465.3 & 3026 & 8.25 & 0.667 \\
\hline $\mathrm{C}_{6} \mathrm{H}_{6}$ & 1.101 & 473.1 & 3062 & 8.32 & 1.096 \\
\hline $\mathrm{HCN}$ & 1.0655 & 527.6 & 3311 & 14.170 & 3.862 \\
\hline $\mathrm{CH} \equiv \mathrm{CH}$ & 1.060 & 556.1 & 3374 & 11.610 & 2.969 \\
\hline $\mathbf{C H}_{3} \mathrm{NH}_{2}$ & 1.099 & 390.4 & 2820 & 6.29 & \\
\hline$\left(\mathrm{CH}_{3}\right)_{3} \mathrm{SiH}$ & $1.485^{e}$ & 377.8 & $2107^{e}$ & 7.03 & 0.971 \\
\hline $\mathrm{SiH}_{4}$ & 1.4798 & 384.1 & 2187 & 8.135 & 1.405 \\
\hline$(\mathrm{CH} 3)_{3} \mathrm{SnH}$ & $1.700^{e}$ & $322^{e}$ & $1815^{e}$ & 7.10 & 1.70 \\
\hline $\mathrm{GeH}_{4}$ & 1.5251 & 349.0 & 2106 & 7.948 & 1.61 \\
\hline $\mathrm{NH}_{3}$ & 1.012 & 452.7 & 3337 & 10.780 & 0.771 \\
\hline $\mathrm{PH}_{3}$ & 1.4200 & 351.0 & 2323 & 9.824 & 1.25 \\
\hline $\mathrm{AsH}_{3}$ & 1.511 & 319.2 & 2116 & $9.85^{f}$ & 1.27 \\
\hline $\mathrm{H}_{2} \mathrm{O}$ & 0.9575 & 498 & 3657 & 13.017 & 1.8277 \\
\hline $\mathrm{OH}$ & 0.96966 & 427.6 & 3737.76 & 13.618 & 1.4611 \\
\hline $\mathrm{CH}_{3} \mathrm{OH}$ & 0.9451 & 436.0 & 3681 & 10.720 & 1.57 \\
\hline $\mathrm{H}_{2} \mathrm{~S}$ & 1.3356 & 381.6 & 2615 & 10.422 & 2.317 \\
\hline $\mathrm{H}_{2} \mathrm{Se}$ & $1.47^{g}$ & 334.9 & 2345 & 9.845 & 2.2125 \\
\hline $\mathrm{CH}_{3} \mathrm{SH}$ & $1.340^{e}$ & 365.3 & $2610^{e}$ & 9.262 & 1.867 \\
\hline $\mathrm{C}_{6} \mathrm{H}_{5} \mathrm{SH}$ & $1.36^{e}$ & 348.5 & $2597^{e}$ & 8.6 & 2.26 \\
\hline $\mathrm{HF}$ & 0.9169 & 569.87 & $3962^{c}$ & 17.423 & 3.448 \\
\hline $\mathrm{HCl}$ & 1.27455 & 431.62 & $2886^{c}$ & 12.968 & 3.6144 \\
\hline $\mathrm{HBr}$ & 1.41444 & 366.35 & $2559^{c}$ & 11.814 & 3.3636 \\
\hline HI & 1.60916 & 298.41 & $2230^{c}$ & 10.451 & 3.059 \\
\hline $\mathrm{CF}_{3} \mathrm{H}$ & 1.098 & 449.5 & 3036 & 8.76 & 1.869 \\
\hline $\mathrm{F}_{2}$ & 1.41193 & 158.78 & $892^{c}$ & 17.423 & 3.448 \\
\hline $\mathrm{Cl}_{2}$ & 1.988 & 242.58 & $557^{c}$ & 12.968 & 3.6144 \\
\hline $\mathrm{Br}_{2}$ & 2.281 & 192.81 & $317^{c}$ & 11.814 & 3.3636 \\
\hline $\mathrm{I}_{2}$ & 2.666 & 151.09 & $213^{c}$ & 10.451 & 3.0590 \\
\hline
\end{tabular}

${ }^{a}$ Bond lengths and bond dissociation energies reported in ref 21 except where noted; boldface letters indicate where the radical is centered after the bond to the hydrogen atom is broken. ${ }^{b}$ Webbook.nist.gov. ${ }^{c}$ Observed frequency, ref 22. ${ }^{d}$ Ref 23. ${ }^{e} \operatorname{Ref} 24 .{ }^{f}$ Estimated from the values of As and $\mathrm{AsH}_{3} .{ }^{g}$ Bond length of $\mathrm{SeH}$.

The comparison between ab initio and ISM reaction energies can be extended to the whole reaction path. Figure 3 a shows that the classical energy-profile of the $\mathrm{H}+\mathrm{H}_{2}$ reaction has a striking resemblance with that of the DMBE-PES. ${ }^{43}$ We recall that $a^{\prime}=0.182$ results from the scaling of ISM to the saddle-

(21) Handbook of Chemistry and Physics, 3rd electronic ed.; CRC Press Inc.: Boca Raton, 2001.

(22) Nakamoto, K. Infrared Spectra of Inorganic and Coordination Compounds J. Wiley: New York, 1963.

(23) Zavitsas, A. A. J. Am. Chem. Soc. 1972, 94, 9.

(24) Zavitsas, A. A.; Chatgilialoglu, C. J. Am. Chem. Soc. 1995, 117, 10645

(25) Johnson, B. G.; Gonzales, C. A.; Gill, P. M. W.; Pople, J. A. Chem. Phys Lett. 1994, 221, 100.

(26) Litwinowicz, J. A.; Ewing, D. W.; Jurisevic, S.; Manka, M. J. J. Phys. Chem. 1995, 99, 9706.

(27) Camaioni, D. M.; Autray, S. T.; Salinas, T. B.; Franz, J. A. J. Am. Chem. Soc. 1996, 118, 2013.

(28) Maity, D. K.; Duncan, W. T.; Truong, T. N. J. Phys. Chem. A 1999, 103 2152 .

(29) González, M.; Hernando, J.; Millán, J.; Sayós, R. J. Chem. Phys. 1999, $110,7326$.

(30) Yu, H.-G.; Nyman, G. J. Chem. Phys. 1999, 111, 6693.

(31) Kraka, E.; Gauss, J.; Cremer, D. J. Chem. Phys. 1993, 99, 5306.

(32) Bian, W.; Werner, H.-J. J. Chem. Phys. 2000, 112, 220.

(33) Kurosaki, Y.; Takayanagi, T. J. Chem. Phys. 1999, 111, 10529.

(34) Yu, X.; Li, S.-M.; Li, Z.-S.; Sun, C.-C. J. Phys. Chem. A 2000, 104, 9207.

(35) Yu, H.-G.; Nyman, G. J. Phys. Chem. A 2001, 105, 2240.

(36) Lynch, G. C.; Truhlar, D. G.; Brown, F. B.; Zhao, J.-G. J. Phys. Chem. 1995, 99, 207.
Table 2. Classical Potential Energy Barriers Calculated by ab Initio Methods $\left(\mathrm{V}^{\ddagger}\right)$ and by ISM $\left({ }^{\ddagger} \mathrm{V}_{\mathrm{cl}}\right)$, in $\mathrm{kJ} / \mathrm{mol}$

\begin{tabular}{|c|c|c|c|c|}
\hline \multirow[b]{2}{*}{ reaction } & \multicolumn{2}{|r|}{ quantum mechanics } & \multicolumn{2}{|c|}{ ISM } \\
\hline & $V^{\ddagger}$ & method $^{a}$ & $m$ & $\Delta^{\ddagger} V_{\mathrm{cl}}$ \\
\hline $\mathrm{H}+\mathrm{H}_{2} \rightarrow \mathrm{H}_{2}+\mathrm{H}$ & $41.5^{b}$ & $\operatorname{CCSD}(\mathrm{T})$ & 1 & 42.3 \\
\hline $\mathrm{CH}_{3}+\mathrm{CH}_{4} \rightarrow \mathrm{CH}_{4}+\mathrm{CH}_{3}$ & $72.4^{c}$ & PMP4 & 1 & 74.6 \\
\hline $\mathrm{C}_{2} \mathrm{H}_{5}+\mathrm{C}_{2} \mathrm{H}_{6} \rightarrow \mathrm{C}_{2} \mathrm{H}_{6}+\mathrm{C}_{2} \mathrm{H}_{5}$ & $64.9^{d}$ & PMP2 & 1 & 76.4 \\
\hline $\mathrm{H}+\mathrm{CH}_{4} \rightarrow \mathrm{H}_{2}+\mathrm{CH}_{3}$ & $61.0^{e}$ & PMP4 & 1 & 55.7 \\
\hline $\mathrm{O}+\mathrm{CH}_{4} \rightarrow \mathrm{OH}+\mathrm{CH}_{3}$ & $55.6^{f}$ & PMP4 & 1.349 & 50.0 \\
\hline $\mathrm{Cl}+\mathrm{CH}_{4} \rightarrow \mathrm{HCl}+\mathrm{CH}_{3}$ & $28.9^{g}$ & $\mathrm{MP} 2 / \mathrm{SAC}$ & 2.161 & 28.4 \\
\hline $\mathrm{NH}_{2}+\mathrm{H}_{2} \rightarrow \mathrm{NH}_{3}+\mathrm{H}$ & $39.8^{h}$ & $\operatorname{CCSD}(\mathrm{T})$ & 1.154 & 44.2 \\
\hline $\mathrm{H}+\mathrm{HCl} \rightarrow \mathrm{H}_{2}+\mathrm{Cl}$ & $21.0^{i}$ & $\mathrm{MRCI}+\mathrm{Q}$ & 1.773 & 21.7 \\
\hline $\mathrm{OH}+\mathrm{H}_{2} \rightarrow \mathrm{H}_{2} \mathrm{O}+\mathrm{H}$ & $23.5^{j}$ & $\operatorname{CCSD}(\mathrm{T})$ & 1.327 & 25.1 \\
\hline $\mathrm{H}+\mathrm{SH}_{2} \rightarrow \mathrm{H}_{2}+\mathrm{SH}$ & $15.1^{k}$ & QCISD(T) & 1.572 & 15.6 \\
\hline $\mathrm{H}+\mathrm{SiH}_{4} \rightarrow \mathrm{H}_{2}+\mathrm{SiH}_{3}$ & $23.2^{l}$ & G2//QCISD & 1.418 & 21.5 \\
\hline $\mathrm{CH}_{3}+\mathrm{HBr} \rightarrow \mathrm{CH}_{4}+\mathrm{Br}$ & $4.9^{m}$ & PMP2 & 2.038 & 11.0 \\
\hline $\mathrm{H}+\mathrm{HBr} \rightarrow \mathrm{H}_{2}+\mathrm{Br}$ & $7.9^{n}$ & MRCISC + SEC & 1.796 & 10.5 \\
\hline $\mathrm{H}_{2}+\mathrm{CN} \rightarrow \mathrm{H}+\mathrm{HCN}$ & $15.1^{\circ}$ & $\operatorname{CAS}(3 \mathrm{E}, 3 \mathrm{O})+1+2$ & 1.793 & 9.2 \\
\hline $\mathrm{H}+\mathrm{PH}_{3} \rightarrow \mathrm{H}_{2}+\mathrm{PH}_{2}$ & $15.1^{p}$ & G2//QCISD & 1.292 & 18.8 \\
\hline $\mathrm{H}+\mathrm{GeH}_{4} \rightarrow \mathrm{H}_{2}+\mathrm{GeH}_{3}$ & $14.8^{l}$ & G2//QCISD & 1.508 & 14.0 \\
\hline $\mathrm{H}_{2}+\mathrm{CCH} \rightarrow \mathrm{H}+\mathrm{HCCH}$ & $18.3^{q}$ & UQCISD & 1.687 & 8.6 \\
\hline $\mathrm{H}_{2}+\mathrm{F} \rightarrow \mathrm{H}+\mathrm{HF}$ & $6.1^{r}$ & $\mathrm{MRCI}+\mathrm{Q}$ & 1.679 & 9.2 \\
\hline $\mathrm{H}+\mathrm{Cl}_{2} \rightarrow \mathrm{HCl}+\mathrm{Cl}$ & $9.4^{s}$ & PMP2 & 1.773 & 7.1 \\
\hline $\mathrm{H}+\mathrm{F}_{2} \rightarrow \mathrm{HF}+\mathrm{F}$ & $7.5^{t}$ & $\mathrm{MRCI}+\mathrm{Q}$ & 1.679 & 0.9 \\
\hline
\end{tabular}

${ }^{a} \mathrm{CCSD}(\mathrm{T})=$ coupled cluster method with single and double excitations and perturbative treatment of triple excitations; $\mathrm{PMPn}=\mathrm{n}$-order spinprojected Møller-Plesset perturbation theory; MRCI+Q = multireference configuration interaction with Davidson correction; CAS $(n E, m O)=(n$ electron, $\mathrm{m}$ orbital) complete active space with single and double excitations; QCISD $(\mathrm{T})=$ quadratic configuration interaction with single and double excitations and perturbative treatment of triple excitations; $\mathrm{SAC}=$ scaling all electron correlation energy; SEC $=$ scaling external electron correlation energy. ${ }^{b}$ Ref 25. ${ }^{c}$ Ref. 26. ${ }^{d}$ Ref. 27. ${ }^{e}$ Ref. 28. ${ }^{f}$ Ref. 29. ${ }^{g}$ Ref. 30. ${ }^{h}$ Ref. 31. ${ }^{i}$ Ref. 32. ${ }^{j}$ Ref. 31. ${ }^{k}$ Ref. 33. ${ }^{l}$ Ref. 34. ${ }^{m}$ Ref. 35. ${ }^{n}$ Ref. 36. ${ }^{o}$ Ref. 37 ${ }^{p}$ Ref. 38. ${ }^{q}$ Ref. 39. ${ }^{r}$ Ref. $40 .{ }^{s}$ Ref. $41 .{ }^{t}$ Ref. 42

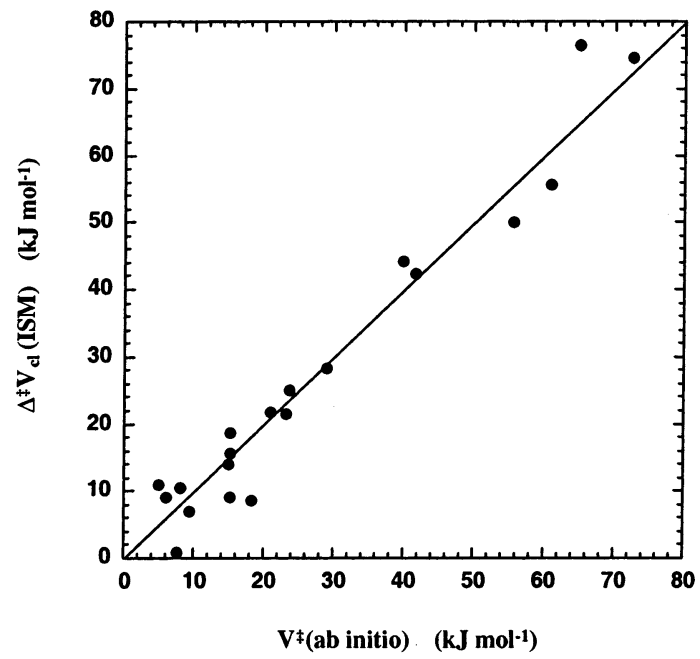

Figure 2. Correlation between the classical energy barriers calculated by ISM $\left({ }^{\ddagger} V_{\mathrm{cl}}\right)$ and those of PES $\left(V^{\ddagger}\right)$, using the data in Table 2 . The correlation coefficient is 0.976 , the slope is 1.03 and the intercept is $-1.0 \mathrm{~kJ} \mathrm{~mol}^{-1}$. The line is the ideal correlation.

point geometry of $\mathrm{H}_{3}$. The energies calculated by ISM along the minimum-energy path do not make use of any empirical adjustment or scaling to kinetic data or transition-state energies.

(37) ter Horst, M. A.; Schatz, G. C.; Harding, L. B. J. Chem. Phys. 1996, 105, 558.

(38) Yu, X.; Li, S.-M.; Liu, J.-Y.; Xu, Z.-F.; Li, Z. S.; Sun, C.-C. J. Phys. Chem. A 1999, 103, 6402

(39) Zhang, X.; Ding, Y.-H.; Li, Z.-S.; Huang, X.-R.; Sun, C.-C. J. Phys. Chem. A 2000, 104, 8375 .

(40) Stark, K.; Werner, H.-J. J. Chem. Phys. 1996, 104, 6515.

(41) Vincent, M. A.; Connor, J. N. L.; Gordon, M. S.; Schatz, G. C. Chem. Phys. Lett. 1993, 203, 415.

(42) Bittererová, M.; Biskupic, S.; Lischka, H.; Jakubetz, W. Phys. Chem. Chem. Phys. 2000, 2, 513. 

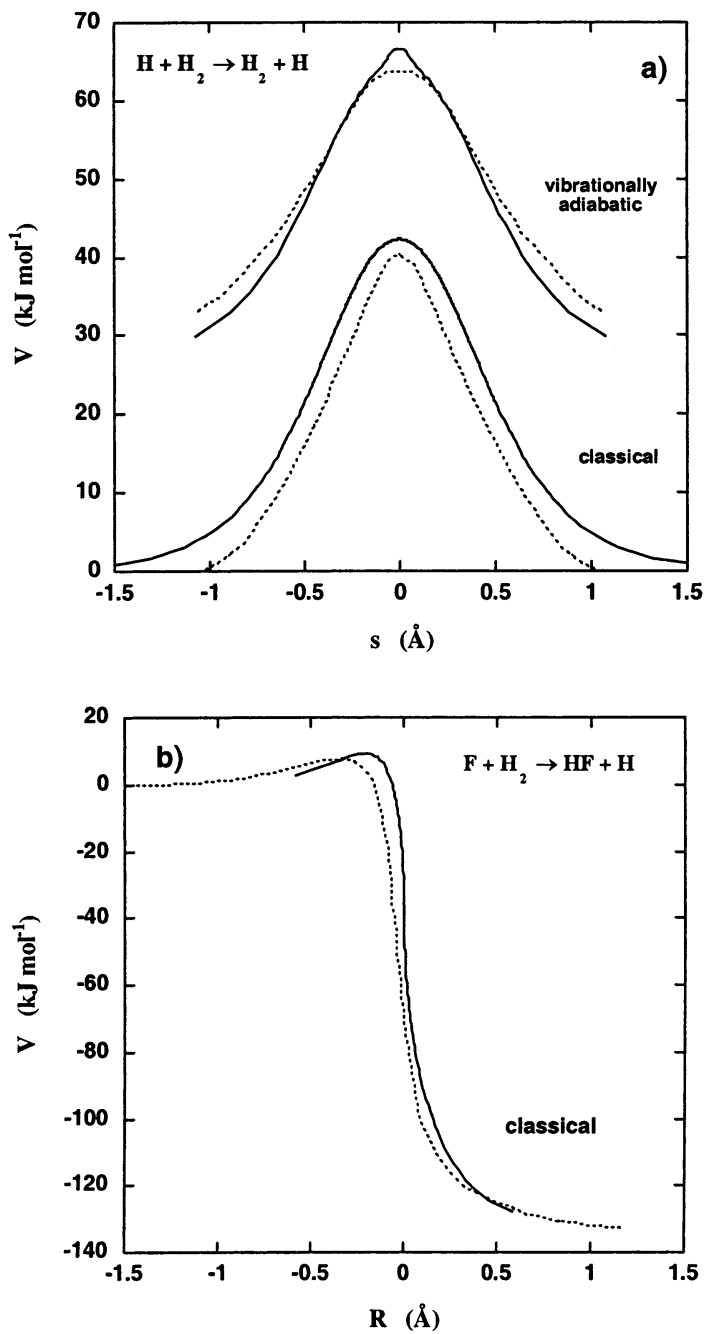

Figure 3. (a) Classical and vibrationally adiabatic paths of ISM (solid line) and DMBE-PES for the $\mathrm{H}+\mathrm{H}_{2}$ hydrogen exchange (dotted line). ${ }^{43}$ the reaction path coordinate is defined as $s= \pm \sqrt{ }(2)\left(l_{\mathrm{HH}}-l_{\mathrm{HH}}^{ \pm}\right)$. (b) Classical path of ISM (solid line) and collinear minimum-energy path of the SWPES (dotted line) $)^{40}$ for the $\mathrm{F}+\mathrm{H}_{2}$ reaction; the reaction path coordinate is defined as $R= \pm\left(l_{\mathrm{HF}}+l_{\mathrm{HH}}-r_{\mathrm{min}}\right)$, where $l_{\mathrm{HF}}$ and $l_{\mathrm{HH}}$ are the bond distances for every point on the minimum-energy path, and $r_{\min }$ is the smallest value of the sum of these distances.

The minimum-energy path of the $\mathrm{F}+\mathrm{H}_{2}$ reaction calculated by us is compared with that of the SW-PES in Figure $3 b .{ }^{40}$ The similarity between the classical reaction paths of ISM and those of ab initio calculations is also observed for polyatomic systems, as illustrated by the $\mathrm{H}+\mathrm{CH}_{4}$ system in Figure $4 \mathrm{a}$, and heavy-light-heavy systems, as illustrated by the $\mathrm{Cl}+\mathrm{HCl}$ exchange in Figure 4b. The detailed agreement between ISM and ab initio calculations strengthens our confidence in the underlying principles of the model and drives the formulation of structure-reactivity relationships.

The more exothermic reactions have smaller barriers, as expected from the empirical Bell-Evans-Polanyi (BEP) relationship, ${ }^{47,48} E_{\mathrm{a}}=\alpha \Delta H^{0}+E_{\mathrm{a}}{ }^{0}$, where $\alpha$ is a constant and $E_{\mathrm{a}}{ }^{0}$

(43) Garrett, B. C.; Truhlar, D. G.; Varandas, A. J. C.; Blais, N. C. Int. J. Chem. Kinet. 1986, 18,1065

(44) Kurosaki, Y.; Takayanagi, T. J. Chem. Phys. 1999, 110, 10830.

(45) Espinosa-Garcia, J. J. Phys. Chem. A 2001, 105, 134.

(46) Garrett, B. C.; Truhlar, D. G.; Wagner, A. F.; Dunning, T. H., Jr. J. Chem Phys. 1983, 78, 4400.

(47) Bell, R. P. Proc. R. Soc. London 1936, A154, 414

(48) Evans, M. G.; Polanyi, M. Trans. Faraday Soc. 1936, 32, 1333.
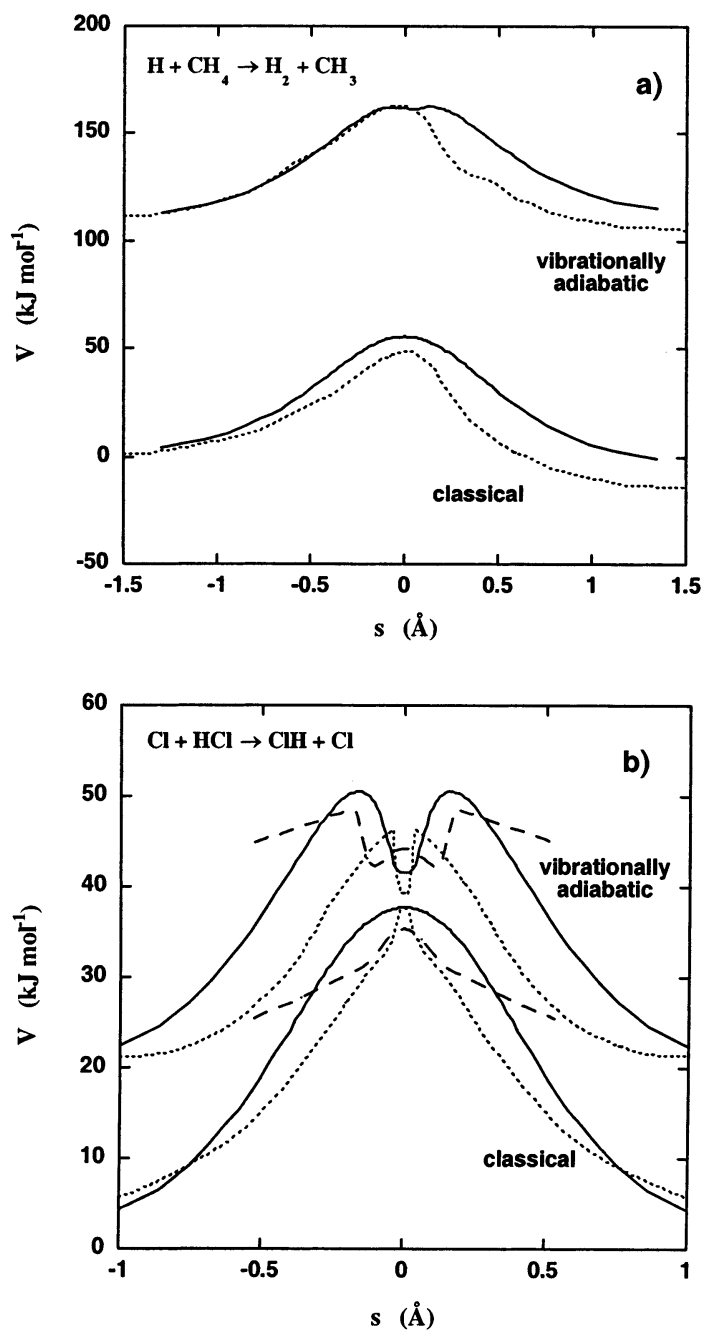

Figure 4. (a) Classical and vibrationally adiabatic paths of ISM (solid line) and LEPS-PES (dotted line) ${ }^{44}$ for the $\mathrm{H}+\mathrm{CH}_{4}$ hydrogen transfer; the difference in ZPE at $s=-\infty$ between the two vibrationally adiabatic paths $\left(90 \mathrm{~kJ} \mathrm{~mol}^{-1}\right)$ was added to ISM. (b) Classical and vibrationally adiabatic paths of ISM (solid line), collinear LEPS-PES (dashed line) ${ }^{45}$ and POLCI/ D-PES (dotted line) ${ }^{46}$ for the $\mathrm{Cl}+\mathrm{HCl}$ hydrogen exchange.

is the intrinsic barrier. The reactions in Table 2 are organized in order of increasing exothermicity and illustrate this fact. However, there is a very poor (linear or quadratic) correlation between $\Delta V^{0}$ and the energy barriers. The BEP relationship can only be applied to series of closely related reactants. This is not the case of our choice of reactions, which emphasizes the need to account for reactivity parameters other than the reaction energy.

The electrophilicity index has a dramatic effect in the classical barrier. For example, the $\mathrm{CH}_{3}+\mathrm{CH}_{4}$ and $\mathrm{Cl}+\mathrm{CH}_{4}$ reactions have similar Morse curves, except for the value of $m$. Increasing $m$ by a factor of 2 decreases the barrier by approximately the same factor. The large value of $m$ of the $\mathrm{Cl}+\mathrm{CH}_{4}$ system underscores the importance of electronic effects.

The scaling by the equilibrium bond-lengths, eq 4 , implies that, other factors being equal, the classical barriers increase with $\left(l_{\mathrm{BC} \text {,eq }}+l_{\mathrm{AB} \text {,eq }}\right)$. This is verified for the reactions $\mathrm{H}+\mathrm{H}_{2}$ and $\mathrm{CH}_{3}+\mathrm{CH}_{4}$. They are both isothermic and their Morse curves are very similar, except for the bond lengths. The sum of equilibrium bond-lengths increased by $47 \%$ and led to a $74 \%$ increase in the classical barrier. 
The relation between bond lengths and bond orders, eq 4 , implies that the sum of bond extensions increases with the reaction energy and, consequently, that the "intrinsic barrier" increases with the exothermicity.

3. Activation Energies. The broad fundamental interest of structure-reactivity relationships becomes apparent when the general principles enunciated above are applied to the rationalization and prediction of activation energies of atom transfers in the gas phase and in an extraordinary large number of reactions and reaction conditions. The Arrhenius activation energy is a phenomenological quantity defined as

$$
E_{a}=-R \frac{d \ln k}{d(1 / T)}
$$

It is usually determined expressing the logarithm of measured rate constants, $k$, as a linear function of the reciprocal temperatures. In $\mathrm{H}$-atom abstractions, the experimental activationenergy frequently decreases at lower temperature, revealing the existence of tunneling. On the other hand, at higher temperatures the transition state may be displaced from the saddle point, and the experimental activation-energies are not comparable with the reaction barriers calculated in this work. Thus, for the purpose of comparison between calculated and experimental activation energies, we selected $100 \mathrm{H}$-abstraction reactions from available databases ${ }^{49}$ and reviews ${ }^{24}$ and recalculated, when necessary, the activation energies using rate constants mostly in the 300-1000 temperature range. These activation energies and the temperature range where they are valid are presented as Supporting Information, Table S1.

The activation energy at the mid-temperature $\left(T_{\text {mid }}\right)$ range considered in this work is the average total energy (relative translational plus internal) of all molecules undergoing reaction minus the average total energy of all reactant molecules. ${ }^{50} T_{\mathrm{mid}}$ is sufficiently high to allow the classical equipartition theorem to calculate accurately the mean translational energies and the mean rotational energies of reactants and transition state. On the other hand, $T_{\text {mid }}$ is smaller than the vibrational temperature, and we neglect the contribution of the vibrational partition function to the internal energy. Therefore, $E_{\mathrm{a}}$ can be calculated adding the difference in internal energy between the transition state and the reactants to the vibrationally adiabatic energy barrier

$$
E_{\mathrm{a}}(\mathrm{ISM})=\Delta^{\ddagger} V_{\mathrm{ad}}+T_{\text {mid }} \Delta C_{\mathrm{V}}
$$

where $\Delta C_{\mathrm{V}}=-3 / 2 R$ is the difference in heat capacity between the transition state and the reactants for triatomic systems, under the approximations discussed above. Polyatomic systems involve more degrees of freedom; but here, we retain this approximation as the simplest approach to estimate activation energies. More elaborate methods will be discussed in the calculation of the actual rate constants.

We calculate $\Delta^{\ddagger} V_{\text {ad }}$ from the vibrationally adiabatic path, which is calculated adding the difference in ZPE to the classical energy at each point along the reaction path

$$
V_{\mathrm{ad}}(n)=V_{\mathrm{cl}}(n)+\sum_{i}\left(\frac{1}{2} h c \bar{v}_{i}\right)
$$

(49) NIST, http://kinetics.nist.gov.

(50) Tolman, R. C. J. Am. Chem. Soc. 1920, 42, 2506.

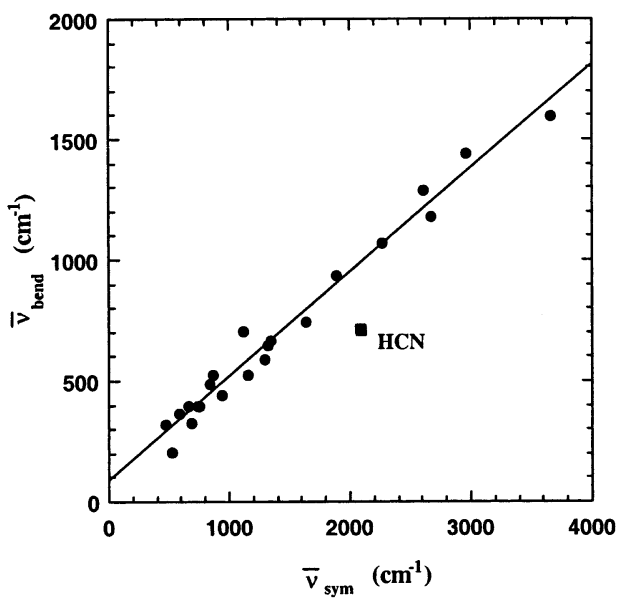

Figure 5. Correlation between bending and symmetric stretching frequencies of triatomic molecules. Systems included in the correlation: $\mathrm{H}_{2} \mathrm{O}, \mathrm{D}_{2} \mathrm{O}$, $\mathrm{H}_{2} \mathrm{~S}, \mathrm{D}_{2} \mathrm{~S}, \mathrm{H}_{2} \mathrm{Se}, \mathrm{D}_{2} \mathrm{Se}, \mathrm{CH}_{2} \mathrm{CO}, \mathrm{SO}_{2}, \mathrm{NO}_{2}, \mathrm{CO}_{2}, \mathrm{CS}_{2}, \mathrm{~F}_{2} \mathrm{O}, \mathrm{Cl}_{2} \mathrm{O}, \mathrm{ClCN}$, $\mathrm{BrCN}$, ICN, SCN ${ }^{-}$, SCO, NNO, $\mathrm{O}_{3}, \mathrm{ClO}_{2}$, and $\mathrm{SCl}_{2}$ from references. ${ }^{22,55}$ The correlation coefficient is 0.989 and the slope is 0.43 . The HCN system does not fit the correlation, presumably because the force constants of the two bonds and the masses of the end atoms are very different.

where $\bar{v}_{\mathrm{i}}$ are the vibration frequencies of the normal modes orthogonal to the reaction coordinate. The $\mathrm{ZPE}$ of $\mathrm{BC}$ is given by its vibration frequency, which is one of the parameters used to calculate its Morse curve. The ZPE of a linear triatomic transition state is calculated using its stretching and bending frequencies. Several strategies have been followed to incorporate ZPE changes in reactivity models. The simplest is to take transition state $\mathrm{ZPE}, Z^{\ddagger}$, as an average, ${ }^{23}$ or a weighted average, ${ }^{51}$ of that of the $\mathrm{BC}$ and $\mathrm{AB}$ bonds. Garrett et al. augmented the $\mathrm{BEBO}$ and the Agmon-Levine methods by including an antiMorse bending potential. ${ }^{52} \mathrm{We}$ estimate the symmetric and antisymmetric stretching frequencies from equation of Wilson for a linear triatomic molecule, ${ }^{53}$ with the neglect of the interaction between bending and stretching. This requires forceconstants for the fractional bonds in the $\{\text { A...B...C }\}^{\ddagger}$ transition state, that are calculated with the equation of Bürgi and Dunitz ${ }^{54}$

$$
\begin{gathered}
f_{\mathrm{bc}}=2 D_{\mathrm{BC}}\left(\beta_{\mathrm{BC}}\right)^{2}(1-n)^{2 \alpha \beta_{\mathrm{BC}}} \\
f_{\mathrm{ab}}=2 D_{\mathrm{AB}}\left(\beta_{\mathrm{AB}}\right)^{2} n^{2 \alpha \beta_{\mathrm{AB}}}
\end{gathered}
$$

The frequencies thus obtained are multiplied by a switching function that provides the correct asymptotic limits: when $n \rightarrow 0$ then $\bar{v}_{\text {asym }} \rightarrow \bar{v}_{\text {BC }}$ and $\bar{v}_{\text {sym }} \rightarrow 0$, when $n \rightarrow 0.5$ then $\bar{v}_{\text {asym }} \rightarrow 0$ and $\bar{v}_{\text {sym }} \rightarrow 1 / 2 \pi \sqrt{w}$, when $n \rightarrow 1$ then $\bar{v}_{\text {asym }} \rightarrow \bar{v}_{\mathrm{AB}}$ and $\bar{v}_{\text {sym }} \rightarrow 0$. We designate by $w$ the quantity $\mathrm{f} / \mu$, that Wilson represented by $\delta$.

The reaction path of ISM does not offer a method to calculate the bending angle or the frequency of the bending mode at the transition state. A bird's-eye survey over many triatomic systems ${ }^{22,55}$ reveals that the symmetric stretching and bending frequencies are linearly related, Figure 5. We use this empirical relation (slope $=0.43$ ) to get the bending frequency from thesymmetric stretching one and to formulate the zero-point

(51) Gilliom, R. D. J. Am. Chem. Soc. 1977, 99, 8399

(52) Garrett, B. C.; Truhlar, D. G.; Magnuson, A. W. J. Chem. Phys. 1982, 76, 2321.

(53) Wilson, E. B., Jr. J. Chem. Phys. 1939, 7, 1047

(54) Bürgi, H.-B.; Dunitz, J. D. J. Am. Chem. Soc. 1987, 109, 2924

(55) Herzberg, G. Molecular Spectra and Molecular Structure. II. Infrared and Raman Spectra of Polyatomic Molecules; Van Nostrand: New York, 1945. 


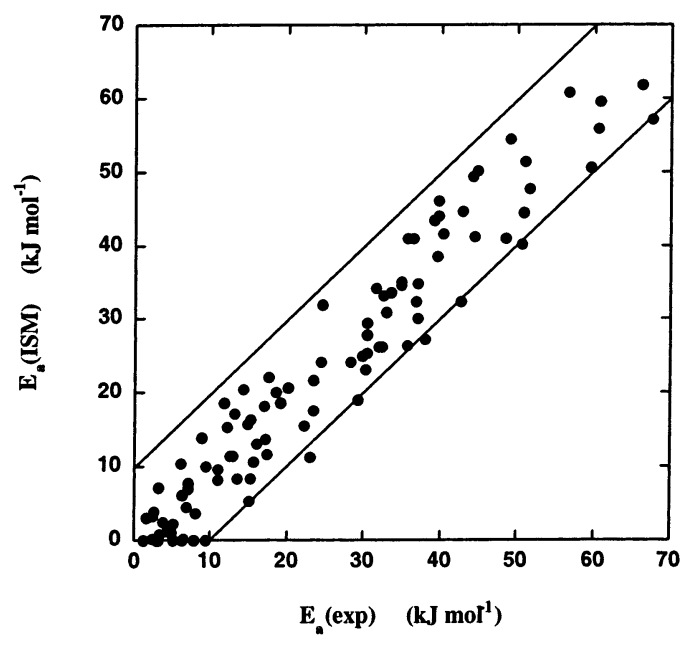

Figure 6. Correlation between the activation energies calculated by ISM according to eq 10, and the experimental activation energies of $\mathrm{H}$-abstraction reactions. The correlation coefficient is 0.965 , the slope is 0.97 and the intercept is $-0.99 \mathrm{~kJ} \mathrm{~mol}^{-1}$.

energy of the transition state as

$$
\mathrm{Z}^{\ddagger}=\frac{1}{2} h c\left[\bar{v}_{\mathrm{sym}}+2\left(0.43 \bar{v}_{\mathrm{sym}}\right)\right]
$$

The equation above emphasizes the fact that we are calculating the bending contribution from the symmetric stretching, and that we assume a collinear transition state, i.e., there are two degenerate bendings.

Figure 6 compares the ISM and experimental activation energies for the $100 \mathrm{H}$-abstraction reactions selected from the available experimental data. They involve the breaking of $\mathrm{HH}$, $\mathrm{CH}, \mathrm{SiH}, \mathrm{GeH}, \mathrm{SnH}, \mathrm{NH}, \mathrm{PH}, \mathrm{AsH}, \mathrm{OH}, \mathrm{SH}, \mathrm{HF}, \mathrm{HCl}, \mathrm{HBr}$, and $\mathrm{HI}$ bonds. Nearly all the calculated activation energies are within $10 \mathrm{~kJ} \mathrm{~mol}^{-1}$ of the experimental ones. For this set of data ISM gives an average error of $4.0 \mathrm{~kJ} \mathrm{~mol}^{-1}$ and a standard deviation of $5.0 \mathrm{~kJ} \mathrm{~mol}^{-1}$. The modified BEBO method published by Gilliom, ${ }^{51}$ gives an average error of $6.6 \mathrm{~kJ} \mathrm{~mol}^{-1}$ and a standard deviation of $9.0 \mathrm{~kJ} \mathrm{~mol}^{-1}$, using his data for rare gas diatomic clusters and the Morse curves of this work and those of Zavitsas. ${ }^{23}$ This comparison clearly shows that ISM gives more reliable activation energies than the BEBO method. Moreover, our method gives accurate reaction paths even for systems involving dramatic changes in zero-point energies, such as the $\mathrm{Cl}+\mathrm{HCl}$ exchange shown in Figure $4 \mathrm{~b}$. The original BEBO method predicts that the $\mathrm{Cl}-\mathrm{H}-\mathrm{Cl}$ species is stable by $5.9 \mathrm{~kJ} \mathrm{~mol}^{-1}$ relative to isolated reactants, and the modified BEBO method calculates a very flat surface near the transition state and a $2.2 \mathrm{~kJ} \mathrm{~mol}^{-1}$ barrier, that is 10 times smaller than the actual barrier.

The success of ISM in calculating the activation energies of such a large variety of systems without fitting any parameters is rooted in its sound physical basis, demonstrated in the previous section. The trends in reactivity formulated in that section are of general usefulness. For example, the reactants with larger electrophilicity indices have much smaller activation energies for similar reaction energies, and the breaking of the shorter $\mathrm{HH}$ bonds leads to smaller activation energies than that of the longer $\mathrm{CH}$ bonds.

4. Rate Constants. The ultimate goal of a reactivity model is to predict the rate constant of any reaction in any reaction conditions with the level of accuracy of experimental techniques. Only the rates of the simplest systems in the gas phase have been calculated to that level of accuracy. Here, we show how Transition-State Theory (TST) can be used with the transitionstate structures and energies estimated with ISM, to calculate accurately the rate constants of diverse and complex atomtransfer reactions.

According to TST, the rate constant is given by

$$
k=\kappa(T) \frac{k_{\mathrm{B}} T}{h} \sigma \frac{Q^{\ddagger}}{Q_{\mathrm{A}} Q_{\mathrm{BC}}} \exp \left(-\frac{\Delta^{\ddagger} V_{\mathrm{ad}}}{R T}\right)
$$

where $\kappa$ is a tunneling correction, $\sigma$ a statistical factor and the $Q_{\mathrm{i}}$ represent the partition functions of transition state and reactants. Equation 14 can be employed if the energy variation along the reaction path and the harmonic vibrational frequencies of the normal modes orthogonal to that path are known. These can be obtained using ISM.

The transition-state geometry given by ISM allows for the calculation of the transition-state moment of inertia. The moment of inertia of the reactants is that of the $\mathrm{BC}$ diatomic (or assumed diatomic) molecule. This information suffices to calculate the ratio of the rotational partition functions. The ratio of the vibrational partition functions can be estimated from the vibration frequencies discussed above.

Representative vibrationally adiabatic paths calculated by ISM are compared with ab initio results for prototypical systems in Figures 3 and 4 . The reasonable agreement between the vibrationally adiabatic paths of ISM and those of high-level ab initio calculations suggests that we can employ ISM vibrationally adiabatic paths together with the semiclassical approximation of Truhlar and Garrett ${ }^{56}$ to calculate tunneling corrections.

The $\mathrm{H}+\mathrm{H}_{2}$ exchange is the simplest of all atom-transfer reactions and has been studied in great detail. It gives us the opportunity to make a detailed comparison between our results with those of very accurate calculations, as well as with experimental measurements. Figure 7a compares ISM/scTST absolute rate-constant calculations with experimental values and with the improved canonical variational TST rate-constants with least-action ground-state transmission coefficients (ICVT/LAG) using the DMBE-PES. ${ }^{43}$ There is an excellent agreement over all the temperature range. At $200 \mathrm{~K}$ ISM/scTST rates tend to exceed the ICVT/LAG ones, presumably because ISM gives a vibrationally adiabatic path that is slightly thinner than that of the DMBE-PES. Our tunneling corrections are 11.3 at $300 \mathrm{~K}$ and 520 at $200 \mathrm{~K}$, whereas Garrett et al. calculated 6.93 and 95.4 with the DMBE-PES, and 8.53 and 136 with the LSTHPES. ISM/scTST and ICVT/LAG rates agree within a factor of 2 at $200 \mathrm{~K}$, because some of the difference in tunneling corrections is compensated by a small difference in zero-point energies. In Figure $7 \mathrm{~b}$ we compare the ISM/scTST rate constants for isotope variants of this reaction, $\mathrm{H}+\mathrm{D}_{2}$ and $\mathrm{D}+\mathrm{H}_{2}$, with the experimental results. Again, there is a remarkable agreement between calculated and experimental rates. At $200 \mathrm{~K}$, the rates calculated for the $\mathrm{D}+\mathrm{H}_{2}$ system are still within a factor of 2 from the experimental ones. Their difference can be assigned to an overestimate of the tunneling corrections. At $200 \mathrm{~K}$, ICVT/ LAG calculations with the DMBE-PES give a tunneling

(56) Garrett, B. C.; Truhlar, D. G. J. Phys. Chem. 1979, 83, 2921. 

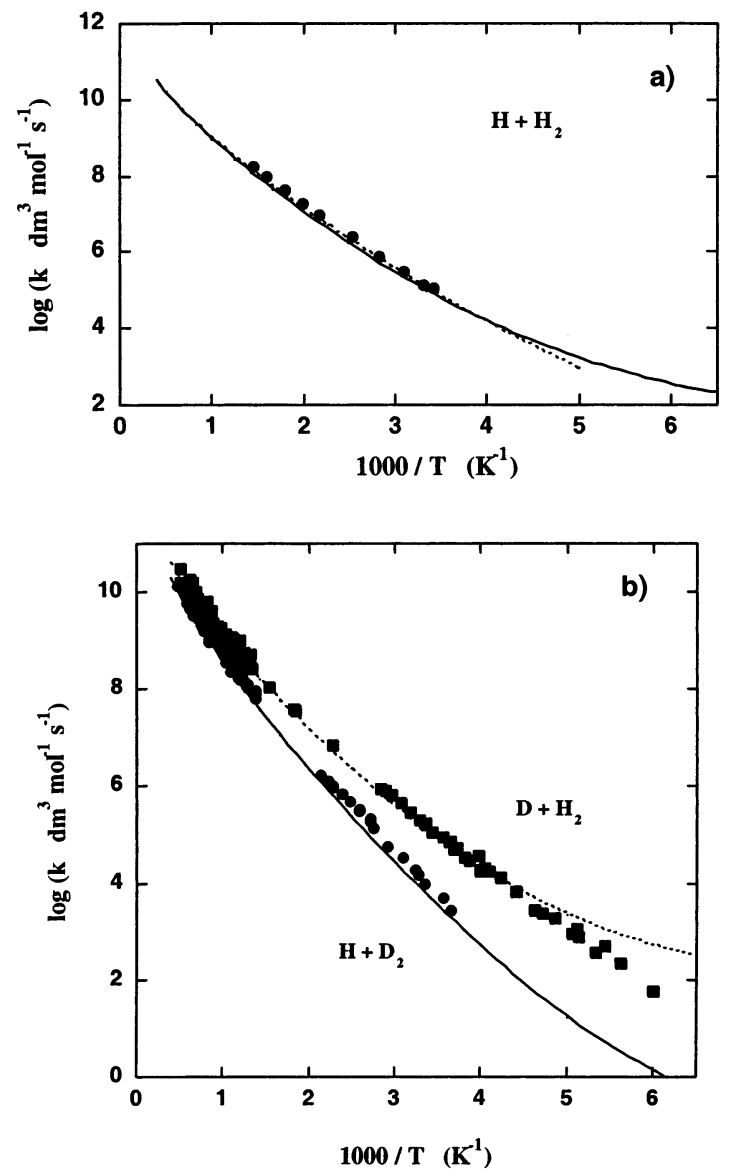

Figure 7. (a) Arrhenius plots of absolute ISM (solid line) and experimental rate-constants for the $\mathrm{H}+\mathrm{H}_{2}$ exchange as a function of the reciprocal absolute temperature; Points: experimental relative rates measured by Quickert and Le Roy ${ }^{57}$ converted to absolute rate-constants using the expression of Michael ${ }^{58}$ dotted line ICVT/LAG thermal rate-constants calculated with the DMBE-PES. ${ }^{43}$ (b) Arrhenius plots of absolute ISM and experimental rate-constants for the $\mathrm{H}+\mathrm{D}_{2}$ (solid line and circles) and $\mathrm{D}$ $+\mathrm{H}_{2}$ (dotted line and squares) reactions. ${ }^{58,59}$

correction of 57 and we calculate 108 . At $300 \mathrm{~K}$ this difference practically disappears, 5.6 vs. 4.8 . At $2400 \mathrm{~K} \mathrm{ISM/scTST} \mathrm{rates}$ remain within a factor of 2 of ICVT/LAG rates for the $\mathrm{D}+\mathrm{H}_{2}$ system.

ISM/scTST can readily be applied to a large variety of systems without additional approximations. Figure 8 illustrates the results of its application to the systems $\mathrm{H}+\mathrm{HX}$, where $\mathrm{X}$ $=\mathrm{F}, \mathrm{Cl}, \mathrm{Br}$ and $\mathrm{I}$. Once again, the experimental rates are very well reproduced, including the 30 orders of magnitude covered by the $\mathrm{I}+\mathrm{H}_{2}$ reaction. ${ }^{60}$ All these systems have similar $m$ values, and their relative reactivity is controlled by the differences in HX bond dissociation energies. The performance of ISM/scTST does not result from a judicious choice of parameters, because our model does not involve any adjustable parameters, or from a compensation of errors, because all the details of the systems are reproduced. For example, the experimental rate-constants for the $\mathrm{Mu}+\mathrm{HBr}$ reaction $(\mathrm{Mu}=$

(57) Quickert, K. A.; Le Roy, D. J. J. Chem. Phys. 1970, 53, 1325

(58) Michael, J. V. J. Chem. Phys. 1990, 92, 3394.

(59) (a) Jayaweera, I. S.; Pacey, P. D. J. Phys. Chem. 1990, 94, 3614. (b) Westenberg, A. A.; de Haas, N. J. Chem. Phys. 1967, 47, 1393. (c) Schulz, W. R.; Le Roy, D. J. Can. J. Chem. 1964, 42, 2480. (d) Michael, J. V.; Fisher, J. R. J. Phys. Chem. 1990, 94, 3318. (e) Mitchell, D. N.; Le Roy, D. J. J. Chem. Phys. 1973, 58, 3449.

(60) Michael, J. V.; Kumaran, S. S.; Su, M.-C.; Lim, K. P. Chem. Phys. Lett. 2000, 319, 99 .

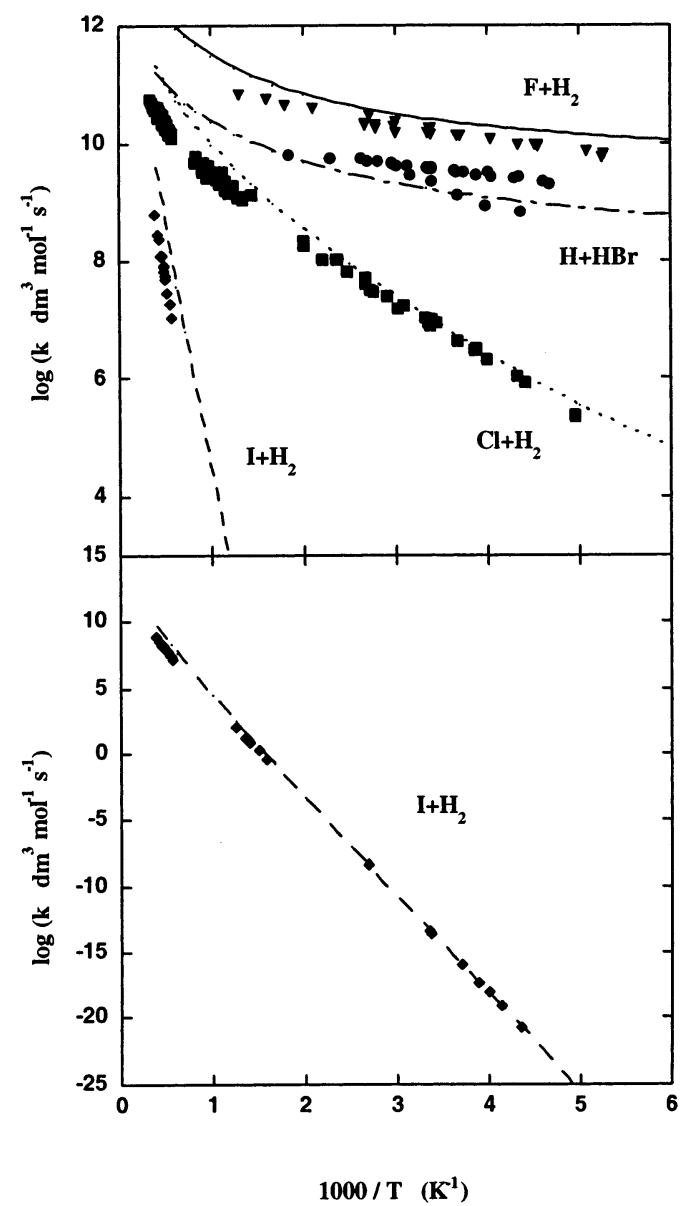

Figure 8. Arrhenius plots of absolute ISM and experimental rate-constants for the $\mathrm{F}+\mathrm{H}_{2}$ (solid line and triangles), ${ }^{62-65} \mathrm{Cl}+\mathrm{H}_{2}$ (dotted line and squares), ${ }^{66-69} \mathrm{H}+\mathrm{HBr}$ (dash-dotted line and circles), ${ }^{70-72}$ and $\mathrm{I}+\mathrm{H}_{2}$ (dashed line and lozenges). ${ }^{60,73-75}$

Muoniun), have been measured at very low temperatures and provide another critical test to the accuracy of ISM/scTST. The experimental value at $206 \mathrm{~K}$ is $8.3 \times 10^{9} \mathrm{~mol}^{-1} \mathrm{dm}^{3} \mathrm{~s}^{-1},{ }^{61}$ which should be compared with the ISM/scTST value of $7.4 \times 10^{9}$ $\mathrm{mol}^{-1} \mathrm{dm}^{3} \mathrm{~s}^{-1}$. At this temperature, we calculate a tunneling correction of 1996 and the ICVT/LAG method with a LEPS surface gives $1150 .{ }^{36}$

The experimental rate-constants of the $\mathrm{H}^{\prime}+\mathrm{XH}^{\prime \prime} \rightarrow \mathrm{H}^{\prime} \mathrm{X}+$ $\mathrm{H}^{\prime \prime}$ halogen exchanges, where the $\mathrm{H}$ are marked differently to represent isotope variants, are not as well established as the competing $\mathrm{H}$-atom abstractions. Table 3 presents some of the experimental data available for these reactions and compares it with ISM/scTST and ICVT/LAG calculations. The thermal rateconstants of the F-exchanges have only been measured at high temperatures, and upper limits in the $2100-3900 \mathrm{~K}$ temperature range were established. The relative rates of removal of vibrationally excited HF by $\mathrm{D}$ atoms indicate that the barrier for the exchange reaction is high, ${ }^{76,77}$ but contradictory inter-

(61) Gonzalez, A. C.; Tempelmann, A.; Arseneau, D. J.; Fleming, D. G.; Senba, M.; Kempton, J. R.; Pan, J. J. J. Chem. Phys. 1992, 97, 6309.

(62) Persky, A.; Kornweitz, H. Int. J. Chem. Kinet. 1997, 29, 67.

(63) Stevens, P. S.; Brune, W. H.; Anderson, J. G. J. Phys. Chem. 1989, 93 4068.

(64) Würtzberg, E.; Houston, P. J. Chem. Phys. 1980, 72, 4811.

(65) Heidner, R. F., III; Bott, J. F.; Gardner, C. E.; Melzer, J. E. J. Chem. Phys. 1980, 72, 4815 .

(66) Kumaran, S. S.; Lim, K. P.; Michael, J. V. J. Chem. Phys. 1994, 101, 9487.

(67) Kita, D.; Stedman, D. H. J. Chem. Soc., Faraday Trans. 2 1982, 78, 1249. 
Table 3. Rate Constants for Halogen-Atom Transfer Constants

\begin{tabular}{lrcccc}
\hline & \multicolumn{1}{c}{$\begin{array}{c}k_{\text {exp }} \\
\mathrm{dm}^{3} \mathrm{~mol}^{-1} \mathrm{~s}^{-1}\end{array}$} & $\begin{array}{c}k_{\text {ISM }} \\
\mathrm{dm}^{3} \mathrm{~mol}^{-1} \mathrm{~s}^{-1}\end{array}$ & $\begin{array}{c}k_{\text {ICVT }} \\
\mathrm{dm}^{3} \mathrm{~mol}^{-1} \mathrm{~s}^{-1}\end{array}$ \\
\hline $\mathrm{H}+\mathrm{DF}$ & 300 & $<7.6 \times 10^{7}$ & 79 & $2.1 \times 10^{1}$ & \\
& 2100 & & & $8.0 \times 10^{8}$ & \\
$\mathrm{D}+\mathrm{HCl}$ & 295 & $(2 \pm 2) \times 10^{5}$ & 80 & $8.1 \times 10^{3}$ & $3.8 \times 10^{-3 a}$ \\
& 1000 & $(9.6 \pm 5.5) \times 10^{7}$ & & $1.2 \times 10^{8}$ & \\
$\mathrm{D}+\mathrm{HBr}$ & 295 & $7.8 \times 10^{6}$ & 81 & $1.7 \times 10^{4}$ & $1.55 \times 10^{2 b}$ \\
$\mathrm{H}+\mathrm{F}_{2}$ & 300 & $9.2 \times 10^{8}$ & 82 & $8.2 \times 10^{9}$ & $2.0 \times 10^{9 c}$ \\
& 300 & $8.0 \times 10^{9}$ & 83 & & \\
$\mathrm{H}+\mathrm{Cl}_{2}$ & 298 & $5.8 \times 10^{9}$ & 84 & $6.5 \times 10^{8}$ & $2.8 \times 10^{10 d}$ \\
$\mathrm{H}+\mathrm{Br}_{2}$ & 295 & $4.1 \times 10^{10}$ & 85 & $1.4 \times 10^{9}$ & \\
\hline
\end{tabular}

${ }^{a}$ LAG tunneling correction, G3-PES ${ }^{86}{ }^{b}$ LAG tunneling correction, LTBZ-PES ${ }^{36}{ }^{c}$ SCSAG tunneling correction, JOT-PES ${ }^{87} d \mu$ OMT tunneling correction, GHNS-PES. ${ }^{88}$

pretations have been published. ${ }^{78}$ Although the reaction conditions employed may not be comparable to those for the thermal rate-constants, it is plausible that the F-exchange is slow. ISM/ scTST calculations predict that the F-atom exchange should be the slowest of all halogen-atom exchanges. Table 3 shows that ISM/scTST calculations are in better agreement with the experimental data than ICVT/LAG calculations. This is a consequence of the inaccuracy of the PES presently available for these exchanges. Halogen exchanges are thermoneutral, have similar values of $m$ and the $\mathrm{H}-\mathrm{X}$ bond lengths decrease from $\mathrm{Br}$ to $\mathrm{F}$, contrary to their reactivity. Here, our model discloses a new structure-reactivity relationship: the molecular factor that dominates the reactivity in the halogen exchanges also affects the shape of the Morse curves. In fact, if we characterize these shapes by the force constant $f_{\mathrm{HX}}=2 D_{\mathrm{HX}}\left(\beta_{\mathrm{HX}}\right)^{2}$, we have $f_{\mathrm{HBr}}=2503, f_{\mathrm{HCl}}=3120$ and $f_{\mathrm{HF}}=5817 \mathrm{~kJ} \mathrm{~mol}^{-1} \AA^{-2}$. The increase in the force constants along this series dominates the decrease in bond lengths.

Table 3 also presents the rates of $\mathrm{H}+\mathrm{X}_{2} \rightarrow \mathrm{HX}+\mathrm{X}$ halogen atom abstractions. They are very fast because these reactions are very exothermic. ISM/scTST tends to underestimate the rate constant for the $\mathrm{H}+\mathrm{Cl}_{2}$ reaction at $298 \mathrm{~K}$ because it uses a linear transition-state. Dobis and Benson showed that a bent transition-state leads to a 10 -fold increase in $A .{ }^{84} \mathrm{ISM} / \mathrm{scTST}$ predicts that the rate of the $\mathrm{H}+\mathrm{Br}_{2}$ reaction at $298 \mathrm{~K}$ is a factor of 2.2 larger than that of the $\mathrm{H}+\mathrm{Cl}_{2}$ reaction, in good agreement with the factor of 3 experimentally observed. ${ }^{85,89}$ The rates of $\mathrm{X}^{\prime}+\mathrm{HX}^{\prime \prime} \rightarrow \mathrm{X}^{\prime} \mathrm{H}+\mathrm{X}^{\prime \prime}$ hydrogen exchanges are difficult to determine both experimentally and theoretically. However, the exchange with $\mathrm{X}=\mathrm{Cl}$ has been studied in detail, and we

(68) Miller, J. C.; Gordon, R. J. J. Chem. Phys. 1981, 75, 5305.

(69) Lee, J. H.; Michael, J. V.; Payne, W. A.; Stief, L. J.; Whytock, D. A. J. Chem. Soc., Faraday Trans. I 1977, 73, 1530.

(70) Mitchell, T. J.; Gonzalez, A. C.; Benson, S. W. J. Phys. Chem. 1995, 99, 16960.

(71) Talukdar, R. K.; Warren, R. F.; Vaghijiani, G. L.; Ravishankara, A. R. Int J. Chem. Kinet. 1992, 24, 973.

(72) Seakins, P. W.; Pilling, M. J. J. Phys. Chem. 1991, 95, 9878.

(73) Umemoto, H.; Nakagawa, S.; Tsunashima, S.; Sato, S. J. Chem. Phys. 1988 $124,259$.

(74) Lorenz, K.; Wagner, H. G.; Zellner, R. Ber. Bunsen-Ges. Phys. Chem. 1979, 83,556 .

(75) Sullivan, J. H. J. Chem. Phys. 1963, 39, 3001

(76) Bartoszek, F. E.; Manos, D. M.; Polanyi, J. C. J. Chem. Phys. 1978, 69, 933.

(77) Bott, J. F.; Heidner, R. F., III J. Chem. Phys. 1978, 68, 1708.

(78) Kaye, J. A.; Kuppermann, A.; Dwyer, J. P. J. Phys. Chem. 1988, 92, 6595

(79) Bott, J. F. J. Chem. Phys. 1976, 65, 1976.

(80) Endo, H.; Glass, G. P. Chem. Phys. Lett. 1976, 44, 180.

(81) Endo, H.; Glass, G. P. J. Phys. Chem. 1976, 80, 1519.

(82) Cohen, N.; Westberg, K., R. J. Phys. Chem. Ref. Data 1983, 12, 531.

(83) Homann, K. H.; Schweinfurth, H.; Warnatz, J. Ber. Bunsen-Ges. Phys. Chem. 1977, 81, 724.

(84) Dobis, O.; Benson, S. W. J. Phys. Chem. A 2000, 104, 777.

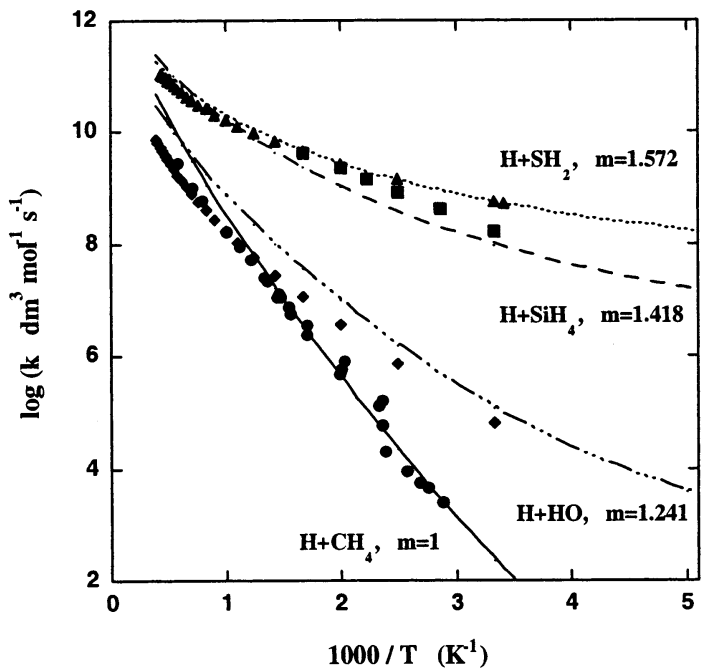

Figure 9. Arrhenius plots of absolute ISM and experimental rate-constants for the $\mathrm{H}+\mathrm{SH}_{2}$ (dotted line and triangles), ${ }^{92,93} \mathrm{H}+\mathrm{SiH}_{4}$ (dashed line and squares), ${ }^{94} \mathrm{H}+\mathrm{HO}$ (dash-dotted line and lozenges), ${ }^{95}$ and $\mathrm{H}+\mathrm{CH}_{4}$ (full line and circles $)^{96}$ hydrogen transfers.

selected it as representative of this type of reactions. Kneba and Wolfum measured this exchange rate at $358 \mathrm{~K}$ and obtained $k$ $=2.5 \times 10^{6} \mathrm{~mol}^{-1} \mathrm{dm}^{3} \mathrm{~s}^{-1} .{ }^{90}$ We calculate $2.5 \times 10^{6} \mathrm{~mol}^{-1}$ $\mathrm{dm}^{3} \mathrm{~s}^{-1}$. The experimental KIE is $8.6 \pm 1.1$ at $312.5 \mathrm{~K}$ and drops to $4.1 \pm 0.4$ at $423 \mathrm{~K},{ }^{91}$ whereas ISM/scTST calculations give 8.6 and 5.1 , respectively.

The application of ISM to atom abstractions from large molecules requires the treatment of modes other than the reactive mode as "spectator" modes. This does not hinder the ability of the model to calculate accurate rate constants and relate structure to reactivity. For example, Figure 9 shows that ISM/scTST rates are in good agreement with the experimental ones for $\mathrm{H}+\mathrm{HR}$ systems where $\mathrm{R}=\mathrm{O}, \mathrm{SH}, \mathrm{CH}_{3}$, and $\mathrm{SiH}_{3}$. A detailed analysis of these systems reveals that abstractions from $\mathrm{CH}_{4}$ and $\mathrm{OH}$ have similar adiabatic reaction-energies $\left(-12.4 \mathrm{~kJ} \mathrm{~mol}^{-1}\right.$ and $-13.3 \mathrm{~kJ} \mathrm{~mol}^{-1}$ ) and the same happens with abstractions from $\mathrm{SH}_{2}$ and $\mathrm{SiH}_{4}\left(-74.2 \mathrm{~kJ} \mathrm{~mol}^{-1}\right.$ and $\left.-77.3 \mathrm{~kJ} \mathrm{~mol}^{-1}\right)$. The difference in reactivity between these two sets of reactants is related to their difference in exothermicity. The subtle reactivity difference within each set is assigned to the differences in their electrophilicity parameters. The systems with larger values of $m$ have smaller barriers, all other factors being approximately equal.

The $\mathrm{H}+\mathrm{CH}_{4}$ reaction is as a prototype of polyatomic $\mathrm{H}$-abstractions. It has been widely studied both theoretically and experimentally and provides a good ground to assess the performance of ISM in polyatomic systems. The replacement of $\mathrm{H}$ by $\mathrm{D}$ in the $\mathrm{H}+\mathrm{CH}_{4}$ reaction leads to an inverse $\mathrm{KIE}$ of $0.55 .^{96,97}$ With ISM we calculate an inverse KIE of 0.73 . This reaction has also been extensively studied in the reverse direction. The experimental $\mathrm{KIE}$ of the $\mathrm{CH}_{3}+\mathrm{H}_{2}$ versus $\mathrm{CH}_{3}$

(85) Wada, Y.; Takayanagi, T.; Umemoto, H.; Tsunashima, S.; Sato, S. J. Chem. Phys. 1991, 94, 4896.

(86) Allison, T. C.; Lynch, G. C.; Truhlar, D. G.; Gordon, M. S. J. Phys. Chem. 1996, 100, 13575

(87) Steckler, R.; Truhlar, D. G.; Garrett, B. C. Int. J. Quantum Chem. Symp. 1986, 20, 495.

(88) González, M.; Hijazo, J.; Novoa, J. J.; Sayós, R. J. Chem. Phys. 1998, $108,3168$.

(89) Jaffe, S.; Clyne, M. A. A. J. Chem. Soc., Faraday Trans. 2 1981, 77, 531

(90) Kneba, M.; Wolfrum, J. J. Phys. Chem. 1979, 89, 69.

(91) Klein, F. S.; Persky, A.; Weston Jr., R. E. J. Chem. Phys. 1964, 41, 1799 
$+\mathrm{D}_{2}$ reaction is now positive and reaches $4.8 \pm 0.4$ at 400 K. ${ }^{98}$ We calculate 7.9 at this temperature. The experimental KIE of the $\mathrm{CH}_{3}+\mathrm{HD}$ versus $\mathrm{CH}_{3}+\mathrm{DH}$ reaction is $2.1 \pm 0.5$ at $467 \mathrm{~K} .{ }^{98}$ We calculate 1.9. The reasonable values obtained with ISM strengthen the idea that this model gives a good account of the reaction coordinate, even in polyatomic systems.

The success of ISM/scTST in the treatment of polyatomic systems is a consequence of the conservation of zero-point energy of the spectator modes along the reaction coordinate and of a cancellation of factors in the ratio of partition functions. For linear transition-states, the ratio of the partition functions for atom+diatomic and atom+polyatomic molecule has the same form

$$
\frac{Q^{\ddagger}}{Q_{\mathrm{A}} Q_{\mathrm{BC}}}=\left(\frac{q_{\mathrm{v}}}{q_{\mathrm{r}}}\right)^{2} P
$$

where $P=\left(q_{\mathrm{r}}\right)^{2} /\left(q_{\mathrm{t}}\right)^{3}$ and $q_{\mathrm{t}}, q_{\mathrm{v}}$, and $q_{\mathrm{r}}$ are the translational, vibrational and rotational partition-functions. The electronic partition-functions are equal to the degeneracy of the ground state and are not explicitly considered in this comparison. Our formulation gives pre-exponential factors of the order of magnitude of $10^{10} \mathrm{~mol}^{-1} \mathrm{dm}^{-3} \mathrm{~s}^{-1}$ for atom + diatomic and atom + polyatomic molecule systems, in good agreement with the pre-exponential factors collected in Table S1. Atom transfers resulting from the attack of diatomic radicals to polyatomic molecules have partition-function ratios of the type $\left(q_{\mathrm{v}} / q_{\mathrm{r}}\right)^{4} P$, and those involving polyatomic radicals and molecules are of the type $\left(q_{\mathrm{v}} / q_{\mathrm{r}}\right)^{5} P$. Typical values are $1 \leq q_{\mathrm{v}} \leq 10$ and $10 \leq q_{\mathrm{r}}$ $\leq 100$, and $\left(q_{\mathrm{v}} / q_{\mathrm{r}}\right)$ may be anywhere from 1 to 0.01 . However, some of the vibrations in polyatomic transition-states are very loose vibrations and sometimes are even regarded as hindered rotations. Thus, $\left(q_{\mathrm{v}} / q_{\mathrm{r}}\right)$ should be rather close to the upper limit. Assuming that the value of the rotational partition function is 3 times that of the vibrational one, we expect that the preexponential factor of diatomic + polyatomic systems should be slightly larger than $10^{9}$ and that of polyatomic + polyatomic systems should be close to $5 \times 10^{8} \mathrm{~mol}^{-1} \mathrm{dm}^{-3} \mathrm{~s}^{-1}$. The data in Table $\mathrm{S} 1$ is consistent with this simple scaling of the preexponential factors. Thus, the pre-exponential factors of atom + polyatomic, diatomic + polyatomic and polyatomic + polyatomic systems can be estimated dividing the value obtained for triatomic transition states by the factors 1,9 , and 27 , respectively.

A critical comparison between experimental and calculated rates can be made at room temperature, because at such temperatures the agreement with the experimental data requires accurate reaction barriers and tunneling corrections. In Table 4 we compare ISM/scTST and experimental rates of atom + molecule, $\mathrm{OH}+$ molecule and $\mathrm{CH}_{3}+$ molecule reactions. The hydroxyl or methyl radical reactions are representative of the rates of diatomic + polyatomic and polyatomic + polyatomic

(92) Yoshimura, M.; Koshi, M.; Matsui, H.; Kamiya, K.; Umeyama, H. Chem. Phys. Lett. 1992, 189, 199.

(93) Schofield, K. J. Phys. Chem. Ref. Data 1973, 2, 25

(94) Goumri, A.; Yuan, W.-J.; Ding, L.; Shi, Y.; Marshall, P. Chem. Phys. 1993 $177,233$.

(95) Tsang, W.; Hampson, R. F. J. Phys. Chem. Ref. Data 1986, 15, 1087.

(96) (a) Marquaire, P.-M.; Dastidar, A. G.; Manthorne, K. C.; Pacey, P. D. Can J. Chem. 1994, 72, 600. (b) Rabinowitz, M. J.; Sutherland, J. W.; Patterson, P. M.; Klemm, R. B. J. Phys. Chem. 1991, 95, 674. (c) Kurylo, M. J.; Timmons, R. B. J. Chem. Phys. 1969, 50, 5076

(97) Kurylo, M. J.; Hollinden, R. B. T. J. Chem. Phys. 1970, 52, 1773.

(98) Shapiro, J. S.; Weston, R. E. J. Phys. Chem. 1972, 76, 1669.
Table 4. Rate Constants at Room Temperature, or Lowest Temperature Experimentally Available, for H-Atom Transfer Reactions $^{a}$

\begin{tabular}{|c|c|c|c|c|c|}
\hline & $\begin{array}{l}T \\
\mathrm{~K}\end{array}$ & $\begin{array}{c}\Delta V_{\mathrm{ad}}{ }^{0} \\
\mathrm{~kJ} \mathrm{~mol}^{-1}\end{array}$ & $m$ & $\begin{array}{c}k_{\text {ISM }} \\
\mathrm{mol}^{-1} \mathrm{dm}^{3} \mathrm{~s}^{-1}\end{array}$ & $\begin{array}{c}k_{\exp } \\
\mathrm{mol}^{-1} \mathrm{dm}^{3} \mathrm{~s}^{-1}\end{array}$ \\
\hline $\mathrm{H}+\mathrm{H}_{2}$ & 300 & 0 & 1 & $9.7 \times 10^{4}$ & $1.3 \times 10^{5}$ \\
\hline $\mathrm{H}+\mathrm{OH}$ & 300 & -9.1 & 1.241 & $1.2 \times 10^{5}$ & $6.3 \times 10^{4}$ \\
\hline $\mathrm{H}+\mathrm{HCl}$ & 300 & -4.7 & 1.773 & $1.6 \times 10^{7}$ & $1.7 \times 10^{7}$ \\
\hline $\mathrm{H}+\mathrm{HBr}$ & 300 & -69.8 & 1.796 & $1.7 \times 10^{9}$ & $3.8 \times 10^{9}$ \\
\hline $\mathrm{F}+\mathrm{H}_{2}$ & 300 & -133.9 & 1.679 & $2.5 \times 10^{10}$ & $1.5 \times 10^{10}$ \\
\hline $\mathrm{H}+\mathrm{HI}$ & 297 & -137.7 & 1.828 & $8.1 \times 10^{9}$ & $1.1 \times 10^{10}$ \\
\hline $\mathrm{H}+\mathrm{CH}_{4}$ & 300 & 2.1 & 1 & $2.3 \times 10^{2}$ & $5.1 \times 10^{2}$ \\
\hline $\mathrm{H}+\mathrm{CH}_{3} \mathrm{CH}_{3}$ & 300 & -13.8 & 1 & $3.5 \times 10^{3}$ & $3.0 \times 10^{4}$ \\
\hline $\mathrm{H}+\mathrm{CH}_{2}\left(\mathrm{CH}_{3}\right)_{2}$ & 300 & -27.7 & 1 & $1.9 \times 10^{4}$ & $6.3 \times 10^{5}$ \\
\hline $\mathrm{H}+\mathrm{CH}\left(\mathrm{CH}_{3}\right)_{3}$ & 300 & -32.5 & 1 & $1.6 \times 10^{4}$ & $6.3 \times 10^{5}$ \\
\hline $\mathrm{H}+\mathrm{CH}_{3} \mathrm{OH}$ & 300 & -34.9 & 1 & $1.2 \times 10^{5}$ & $7.6 \times 10^{5}$ \\
\hline $\mathrm{H}+\mathrm{CH}_{3} \mathrm{CHO}$ & 300 & -62.9 & 1 & $7.8 \times 10^{5}$ & $3.4 \times 10^{7}$ \\
\hline $\mathrm{H}+\mathrm{CH}_{2} \mathrm{O}$ & 298 & -68.2 & 1 & $3.6 \times 10^{6}$ & $2.4 \times 10^{7}$ \\
\hline $\mathrm{H}+\mathrm{NH}_{3}$ & 500 & 16.0 & 1.154 & $4.7 \times 10^{5}$ & $7.1 \times 10^{4}$ \\
\hline $\mathrm{H}+\mathrm{SH}_{2}$ & 300 & -54.7 & 1.572 & $5.6 \times 10^{8}$ & $5.8 \times 10^{8}$ \\
\hline $\mathrm{H}+\mathrm{SiH}_{4}$ & 300 & -52.2 & 1.418 & $9.6 \times 10^{7}$ & $1.2 \times 10^{8}$ \\
\hline $\mathrm{H}+\left(\mathrm{CH}_{3}\right)_{3} \mathrm{Si} H$ & 300 & -58.5 & 1.321 & $1.1 \times 10^{7}$ & $1.8 \times 10^{8}$ \\
\hline $\mathrm{H}+\mathrm{CH}_{3} \mathrm{SH}$ & 296 & -71.0 & 1.505 & $3.9 \times 10^{8}$ & $2.5 \times 10^{8}$ \\
\hline $\mathrm{H}+\mathrm{PH}_{3}$ & 300 & -85.3 & 1.292 & $2.0 \times 10^{8}$ & $2.0 \times 10^{9}$ \\
\hline $\mathrm{H}+\mathrm{GeH}_{4}$ & 300 & -87.1 & 1.508 & $1.2 \times 10^{9}$ & $2.5 \times 10^{9}$ \\
\hline $\mathrm{H}+\mathrm{SeH}_{2}$ & 298 & -101.2 & 1.580 & $2.5 \times 10^{9}$ & $7.1 \times 10^{9}$ \\
\hline $\mathrm{H}+\mathrm{AsH}_{3}$ & 294 & -116.9 & 1.296 & $5.8 \times 10^{8}$ & $1.3 \times 10^{10}$ \\
\hline $\mathrm{F}+\mathrm{CH}_{4}$ & 300 & -131.1 & 2.078 & $4.9 \times 10^{10}$ & $4.8 \times 10^{10}$ \\
\hline $\mathrm{Cl}+\mathrm{CH}_{4}$ & 300 & 6.8 & 2.161 & $4.5 \times 10^{7}$ & $6.3 \times 10^{7}$ \\
\hline $\mathrm{OH}+\mathrm{H}_{2}$ & 300 & -62.0 & 1.327 & $2.6 \times 10^{7}$ & $4.2 \times 10^{6}$ \\
\hline $\mathrm{OH}+\mathrm{CH}_{4}$ & 300 & -59.2 & 1.456 & $4.6 \times 10^{6}$ & $3.9 \times 10^{6}$ \\
\hline $\mathrm{OH}+\mathrm{CH}_{3} \mathrm{CH}_{3}$ & 300 & -75.1 & 1.581 & $8.0 \times 10^{7}$ & $1.5 \times 10^{8}$ \\
\hline $\mathrm{OH}+\mathrm{CH}_{2}\left(\mathrm{CH}_{3}\right)_{2}$ & 300 & -89.0 & 1.660 & $1.0 \times 10^{8}$ & $5.6 \times 10^{8}$ \\
\hline $\mathrm{OH}+\mathrm{CH}\left(\mathrm{CH}_{3}\right)_{3}$ & 300 & -93.8 & 1.750 & $1.2 \times 10^{8}$ & $9.5 \times 10^{8}$ \\
\hline $\mathrm{OH}+\mathrm{CH}_{3} \mathrm{OCH}_{3}$ & 300 & -95.8 & 1.721 & $6.4 \times 10^{8}$ & $1.8 \times 10^{9}$ \\
\hline $\mathrm{OH}+\mathrm{CH}_{3} \mathrm{OH}$ & 300 & -96.2 & 1.637 & $2.1 \times 10^{8}$ & $5.3 \times 10^{8}$ \\
\hline $\mathrm{OH}+\mathrm{CH}_{3} \mathrm{C}_{6} \mathrm{H}_{5}$ & 298 & -122.4 & 1.674 & $8.0 \times 10^{8}$ & $4.2 \times 10^{9}$ \\
\hline $\mathrm{OH}+\mathrm{CH}_{3} \mathrm{CHO}$ & 300 & -124.2 & 1.707 & $3.3 \times 10^{8}$ & $9.5 \times 10^{9}$ \\
\hline $\mathrm{OH}+\mathrm{CH}_{2} \mathrm{O}$ & 300 & -129.5 & 1.576 & $3.5 \times 10^{8}$ & $5.5 \times 10^{9}$ \\
\hline $\mathrm{CH}_{3}+\mathrm{CH}_{4}$ & 350 & 0 & 1 & 1.2 & 0.55 \\
\hline $\mathrm{CH}_{3}+\mathrm{CH}_{3} \mathrm{CH}_{3}$ & 300 & -15.9 & 1 & 0.91 & 4.3 \\
\hline $\mathrm{CH}_{3}+\mathrm{CH}_{2}\left(\mathrm{CH}_{3}\right)_{2}$ & 300 & -29.8 & 1 & 4.0 & $5.7 \times 10^{1}$ \\
\hline $\mathrm{CH}_{3}+\mathrm{CH}\left(\mathrm{CH}_{3}\right)_{3}$ & 300 & -34.6 & 1 & 3.4 & $1.5 \times 10^{2}$ \\
\hline $\mathrm{CH}_{3}+\mathrm{CH}_{3} \mathrm{COCH}_{3}$ & 370 & -27.6 & 1 & $2.7 \times 10^{2}$ & $2.7 \times 10^{2}$ \\
\hline $\mathrm{CH}_{3}+\mathrm{CH}_{3} \mathrm{OCH}_{3}$ & 373 & -36.7 & 1 & $1.4 \times 10^{3}$ & $5.4 \times 10^{2}$ \\
\hline $\mathrm{CH}_{3}+\mathrm{CH}_{3} \mathrm{OH}$ & 300 & -37.1 & 1 & $3.0 \times 10^{1}$ & $1.6 \times 10^{1}$ \\
\hline $\mathrm{CH}_{3}+\mathrm{CH}_{3} \mathrm{NH}_{2}$ & 383 & -48.5 & 1 & $5.5 \times 10^{3}$ & $1.1 \times 10^{3}$ \\
\hline $\mathrm{CH}_{3}+\mathrm{CH}_{3} \mathrm{C}_{6} \mathrm{H}_{5}$ & 373 & -63.2 & 1 & $1.1 \times 10^{4}$ & $1.1 \times 10^{3}$ \\
\hline $\mathrm{CH}_{3}+\mathrm{CH}_{3} \mathrm{CHO}$ & 300 & -65.1 & 1 & $3.5 \times 10^{2}$ & $3.0 \times 10^{3}$ \\
\hline $\mathrm{CH}_{3}+\mathrm{CH}_{2} \mathrm{O}$ & 300 & -70.4 & 1 & $1.7 \times 10^{3}$ & $3.7 \times 10^{3}$ \\
\hline $\mathrm{CH}_{3}+\mathrm{H}_{2} \mathrm{O}$ & 300 & 59.2 & 1.456 & $5.5 \times 10^{-5}$ & $1.1 \times 10^{-4}$ \\
\hline $\mathrm{CH}_{3}+\mathrm{NH}_{3}$ & 350 & 13.8 & 1.170 & 4.3 & $4.9 \times 10^{1}$ \\
\hline $\mathrm{CH}_{3}+\mathrm{NH}_{2} \mathrm{CH}_{3}$ & 383 & -20.5 & 1.144 & $2.7 \times 10^{3}$ & $2.0 \times 10^{3}$ \\
\hline $\mathrm{CH}_{3}+\mathrm{H}_{2} \mathrm{~S}$ & 332 & -56.8 & 1.616 & $1.1 \times 10^{7}$ & $5.0 \times 10^{6}$ \\
\hline $\mathrm{CH}_{3}+\left(\mathrm{CH}_{3}\right)_{3} \mathrm{SiH}$ & 345 & -60.6 & 1.321 & $1.7 \times 10^{5}$ & $3.4 \times 10^{3}$ \\
\hline
\end{tabular}

${ }^{a}$ The experimental data was taken from the NIST Chemical Kinetics Database; ${ }^{49}$ the references to the experimental work can be found in the Supporting Information, Table S2.

systems. Figure 10 shows that ISM/scTST rates are in very good agreement with the experimental data. The rates of $\mathrm{H}+\mathrm{HCR}_{3}$ reactions are slightly underestimated. The calculations could be improved taking into consideration the actual difference between the value of $m$ for these reactions and that for the $\mathrm{H}+\mathrm{H}_{2}$ reference system, given by eq 8 . We resist to make this adjustment of the parameter $m$ (that would increase the correlation coefficient to 0.980 ), because we wish to preserve the simplicity of the model and report only absolute rate calculations. In view of the agreement between calculated and experimental rates, we conclude that ISM provides order of magnitude estimates for the $\mathrm{H}$-abstraction rates of polyatomic systems. 


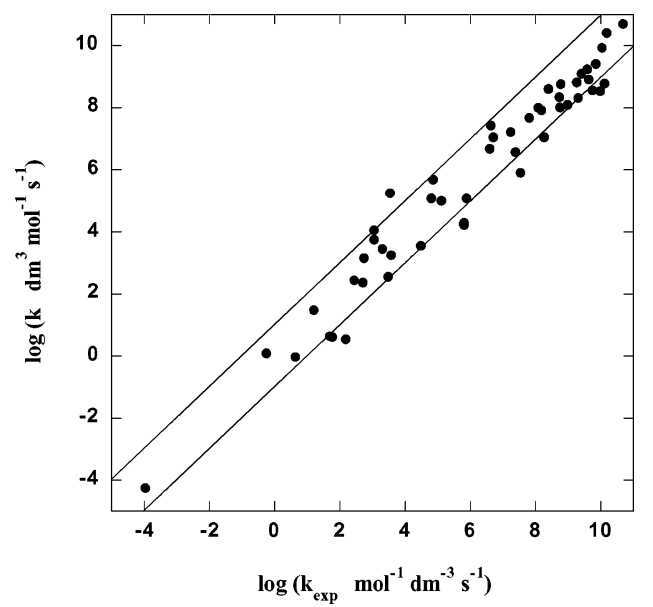

Figure 10. Comparison between experimental rate-constants and absolute rate-constants calculated with ISM for hydrogen abstractions directly involving carbon, hydrogen and one heteroatom. Data from Table 4. The correlation coefficient is 0.976 and the slope is 0.96 .

\section{Conclusions}

ISM relates minimum-energy paths to the properties of reactants and products. Adding zero-point energy corrections and heat capacity differences, it accurately estimates activation energies. ISM provides a quantitative expression for empirical structure-reactivity relationships such as Hammond postulate, linear (or quadratic) free-energy relationships, and for the conditions for which they fail. Furthermore, ISM uncovers new patterns of reactivity, not explicit in other reactivity models, namely:

(i) The so-called "intrinsic-barrier" of a family of reactions tends to increase with $\left|\Delta V^{0}\right|$;

(ii) The reaction barrier increases with the sum of the equilibrium bond-lengths of the reactive bonds; (iii) The reaction barrier decreases with the increase of the electrophilicity index of the reactants.

(iv) Higher force constants lead to higher barriers and asymmetric force-constants change the location of the transition state.

ISM/scTST rates are calculated exclusively from the following parameters of reactants and products: the mass of the atoms, the bond lengths, vibration frequencies, and bond dissociation energies of the reactive bonds, the ionization potential and electronic affinity of the radicals. The temperature dependence of H-atom transfers and their KIE are well reproduced by ISM/ scTST calculations.

The simplicity of the method favors the understanding of how each property of the reactants or products influences the rate of an atom-transfer reaction. ISM links the solution of one system to those of related systems. It can easily be employed to predict the reactivity of atoms or radicals in atom-transfer reactions.

Acknowledgment. We thank Fundação para a Ciência e Tecnologia (Portugal) and FEDER for financial support; project no. POCTI/42536/QUI/2001. M. Barroso acknowledges Fundação para a Ciência e a Tecnologia for financial support (grant $\mathrm{BD} / 1332 / 2000)$.

Supporting Information Available: Algorithm for ISM/ scTST calculations. Input and output for ISM/scTST calculations for an arbitrary system. Table S1 with experimental and calculated activation energies for a series of reactions. Table S2 with rate constants at room temperature and references to the experimental measurements. This material is available free of charge via the Internet at http://pubs.acs.org.

JA029298E 